
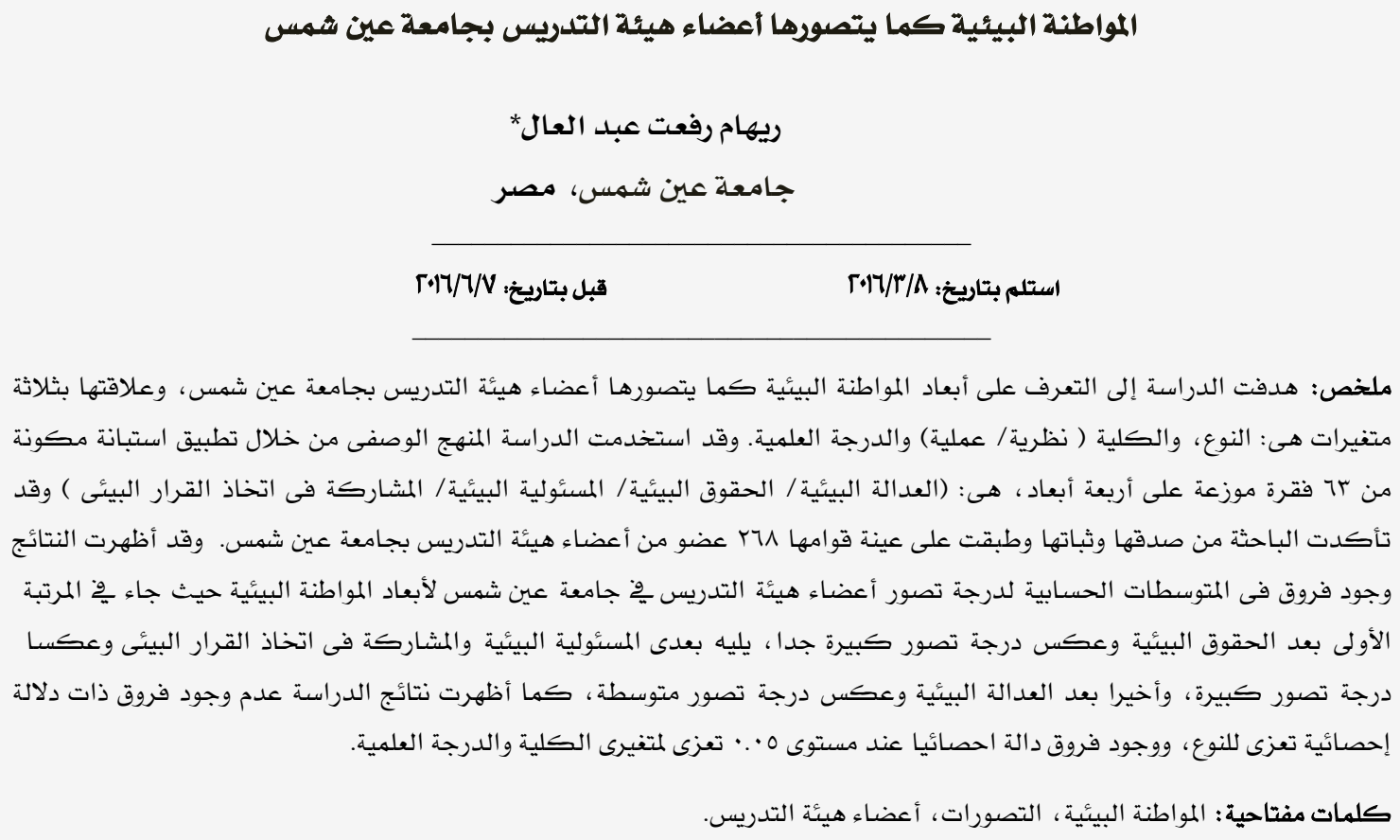

\title{
Environmental Citizenship from the Perspective of University Staff at Ain Shams University
}

Reham R. Abdelaal*

Ain Shams University, Egypt

\begin{abstract}
The study aimed at identifying the dimensions of environmental citizenship from the perspective of university staff members in Ain Shams University, and its relation with some variables including gender, college (theoretical and practical) and scientific degree. The study was done using the descriptive method, and a questionnaire consisting of 63 items distributed on four dimensions (Environmental Justice -Environmental Rights- Environmental Responsibility and participation in environmental decision-making). The researcher checked its validity and reliability and the questionnaire was distributed to a sample consists of 268 University staff Member's. The results of the study showed that there were differences in the average of the degrees of perception of Ain Shams university staff members of dimensions of the environmental citizenship. The dimension of environmental rights came in the first degree, as it reflected a very large degree of perception, followed by both dimensions of environmental responsibility and participation in environmental decision-making, which reflected a large degree of perception, and finally the dimension of environmental justice which reflecteda a medium degree of perception. The study also showed that there no were statistically significant differences related to gender, while there were statistically significant differences at the level of 0.05 related to the variables of college and scientific degree.
\end{abstract}

Keywords: Environmental Citizenship, perspective, university staff members.

*refaatfamily2@yahoo.com 
سومر وأشور وبابل وحضارات مصر والصسين والهند وفارس وأسهمت تلك الحضارات وما انبثق عنها من إيديولوجيات سياسية ِّْ وضع أسس الحرية والمساواة تجاوزت إرادة الحكام، فاتحة بذلك أفاقا رحبة لسعي الإنسان لتأكيد فطرته واثبات ذاته وحق المشاركة الفعالة پِّ اتخاذ القرارات وتحديد الخيارات (الدجانى،

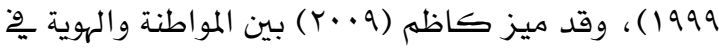
أن المواطنة انتساب جفرايٌّ إلى أرض معينة بينما الهوية انتساب ثقايخ إلى معتقدات وقيم ومعايير معينة ، فى حين ميز الشريدة (0 • ب) بين المواطنة والوطنية اذ اعتبر الوطنية الإطار الفكري النظري للمواطنة، بمعنى أن الوطنية عملية فكرية بينما المواطنة ممارسـة عملية أي مشاركة ؛ فقد يكون الإنسان مواطنا بحكم جنسيته أو مكان ولادته ولكن ليس لديه وطنية تجاه المكان

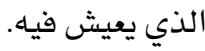
وِوِ القرن العشرين شهد مفهوم المواطنة تطورا اتسهم بالعالمية وتحددت مواصفات المواطنة العالمية بالاعتراف بوجود ثقافات متعددة/ احترام حق الغير وحريته/ احترام الأديان السهماوية والمذاهب المختلفة/ فهم الايديولوجيات السياسية/ فهم اقتصاديات العاله/ الاهتمام بالشؤون

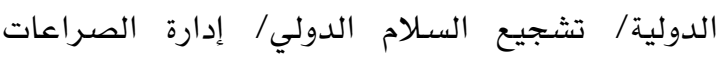
بطريقة اللاعنف (Holmes, 1980). وقد أستتدت المواطنة العالمية على ركيزتين الأولى تهثلت فى عالمية التحديات كعدم المسـاواة الاجتهاعية والاقتصادية، وعدم المسساواة فى امتلاك تقنيات معلومات، والتدهور البيئي وتهديد السـلام، أما الثانية فتمثلت فى أن هناك مجتمعات ذات ديانات وثقافات وأعراف وتقاليد ونظم مختلفة ، ولقد أسفرت اجتهادات المفكرين لتحليل طريخٌ معادلة (عالمية التحديات/ تعددية المجتمعات) عن تفاعلات جديدة تتلخص پِّ صياغة عناصر جديدة للمواطنة، وتأسيس مصطلح جديد وِّ الخطاب المعاصر تحت مسهى (المواطنة العالمية) أو (المواطنة متعددة الأبعاد) والتى شملت (البعد الشخصيالبعد الاجتماعي-البعد المكاني-البعد الزماني) وأوصت المؤسسات السياسية والتربوية تحقيقها من خلال العناصر التالية (الإحساس بالهوية/ التمتع بحقوق
حظيت تتمية المواطنة بهكانة كبيرة وِّ الأجندة التربوية وِّ كثير من دول العالم بحْ العقدين الأخيرين، وظهر هذا جليا فى تحديد الأساليب والاستراتيجيات التي يهكن أن تحقق المواطنة الفعالة (Active Citizenship)، حيث سـاهمت التعددية الثقافية، وأنشطة مؤسسـات المجتهـع المدني، وظهور العولمة فى طرح مفاهيم جديدة مرتبطة بالمواطنة مثل المواطنة العالمية Global) (Digital C Citizenship) Environmental Citizenship) (Green أو المواطنة الخضراء (Citizenship) .Citizenship)

ويرجع مفهوم المواطنة إلى نشأة الحضارات الإنسانية،

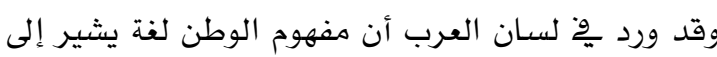
المنزل الذى يقيم فيه الإنسان، فهو وطنه ومحله (ابن

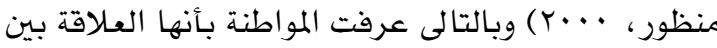
الفرد والدولة كها يحددها قانون تلك الدولة، وبها تتضهنه تلك العلاقة من واجبات وحقوق وما يصاحبها

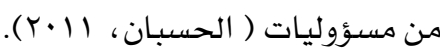
فالمواطنة Citizenship هي صفة المواطن والتي تحدد حقوقه وواجباته الوطنية، وتتميز المواطنة بنوع خاص من ولاء المواطن لوطنه وخدمته ِِّ أوقات السلهم والحرب والتعاون مع المواطنين الآخرين عن طريق العمل المؤسساتي والفردي والتطوعي ِّْ تحقيق الأهداف التي يصبو إليها الجميع وتوحد من أجلها جهود الوطن (بدوى،

.$(19 \wedge r$

وتعد المواطنة أوسع مدى من منطوق الكلمة ، فالمواطنة مشتقة من الوطن وما دام الوطن هو القضية؛ فإن كلمة المواطنة يحتويها إطار أوسع وهو الدولة الوطنية

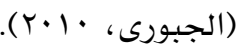
ولقد اقترن مفهوم المواطنة بحركة النضال الإنساني من أجل العدل والمساواة والإنصاف، وكان ذلك قبل أن يستقر مصطلح المواطنة وما يقاربه من مصطلحات الأدبيات السياسية والفكرية والتربوية، وتصاعد النضال وأخذ شكل الحركات الاجتهاعية منذ قيام الحكومات الزراعية ِِّ بلاد الرافدين مرورا بحضارة 
Green Ángel 2005; Smith, 1998) (Dean, 2001; Smith, 2005) Citizenship )، والمواطنة البيئية Environmental Citizenship (Luque, 2005 ) En والمواطنة المستدامة Barry, ) Sustainability Citizenship 2006، والمواطنة البيئية المسئولة Environmentally (Hailwood,2005) Reasonable Citizenship وعلى الرغم هن الانتشـار الواسع لاستخدام هذه المصطلحات، إلا أن العلاقة بين الفكر السياسي الني

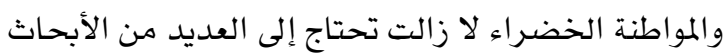
والدراسـات لتوضيحها (MacGregor, 2006).

وعلى الصعيد الآخر عكس التنوع النظري العلاقة الارتباطية بين المواطنة والبيئة حيث ربطت العديد من الدراسـات بين نشاطات الإنسان فى البيئة مثل التدوير، وقلة الاستهلاك وواجبات المواطنـين البيئيين ) Dobson, 2003 )، فى حين يعتبرها البعض من الخيارات الخاصة التى تشهل حق الفرد ٍِِ أن يعيش حياة خضراء. ( Bell, (2005

كما ارتبط مفهوم المواطنة البيئية بهفهوم التتمية المستدامة إنطلاقا من إن الوصول إلى المجتمعات المستدامة يتطلب تحولات يُّ مواقف البشر تجاه البيئة، وهذا ما تسعى إلى تحقيقه "نظرية المواطنة المستدامة (Dobson \& Derek, 2006)

فالمواطنة البيئية هي النظر إلى ما هو أبعد من المصالح الشخصية والمباشـرة للوصول إلى رفاهية المجتهع الأوسع نطاقا (البيئة)، واضعة ِِّ اعتبارها الحفاظ على حقوق واحتياجات الأجيال القادمة؛ من خلال تتمية السلوك

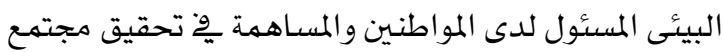
عادل، وهي بهذا المفهوم تهدف إلى توفير السبل لتعزيز الاستدامة الايكولوجية والعدالة البيئية على حد سواء

(Killeen, 2006)

وبما أن الأساس الجوهري للمواطنة يتمثل فى العلاقة المتبادلة بين الوطن والمواطن من خلال الممارسة العملية بينهما ، لذلك نجد أن العلاقة الوطيدة تظهر بين المواطنة والبيئة، فالوطن هو البيئة التي يعيش فيها المواطن ويتفاعل معها ويؤثر فيها ويتأثر بها ، من خلال علاقتته

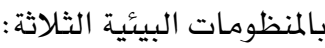

المواطنة/ المسؤوليات والالتزامات والواجبات/ قبول قيم اجتماعية أساسية) (John et al, 2000).

لذلك نجد أن قيم المواطنة فى المناهـ الدراسية وتدريب الطلاب على ممارستها داخل المجتهع يؤدى الى تقدم المجتهع إنطلاقا من كونها تعد مكون أصيل من هن مكونات الدولة الديموقراطية المعاصرة وهى تجسيد لشعب يحترم كل فرد منهم الفرد الآخر والتمسك بالتسامح تجاه التتوع الذى يزخر به المجتمع (أبو غريب،

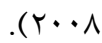

وعلى صعيد آخر اتسمت قضية المواطنة بالجدل فى

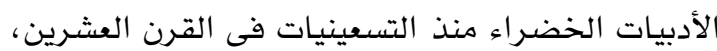
وقد أصبحت بعض المفاهيم مثل المواطنة البيئية تتطوي على روابط بين السياسـات الخضراء ونظريات المواطنة، حيث ظهر مفهوم المواطنة البيئية ِِّ العديد من الدراسـات منذ التسعينيات بوخ الوثائق السياسية والأوساط (Basile, \& White, 2000; الأكاديمية منها دراسـات Florida State Dept. of Environmental Protection, Tallahassee ,2000; Nowak,2009; Lysack,2009; Gebbels, et al,2011; Dimick, ,2015; Robinson, 2015 ; Green, et al ,2016) تلك الدراسات أكدت ; على أهمية التتور البيئى للطلاب والمعلمين كنقطة انطلاق لتحقيق المواطنة البيئية، دعم الشباب لتطوير اتجاهات إيجابية نحو المواطنة البيئية فى ظل المفاهيم

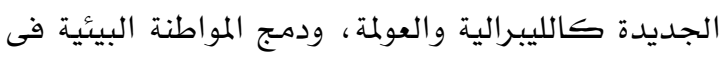

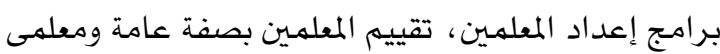
الجغرافيا بصفة خاصة أثناء وبعد الخدمة فى ضوء مدى لرى إنى اكتسابهم لأبعاد المواطنة البيئية ، إعداد وسـائل إرشادية ومنها الملصقات للتوعية بهفهوم المواطنة البيئية وأبعادها فى المدارس والجامعات، ضرورة تقييم المواطنة البيئية والمسئولية البيئية للشركات من خلال المدارس والمصانع والجامعات، وتعزير العمل البيئى والمواطنة البيئية لحل

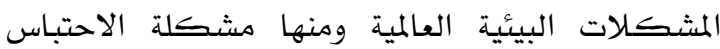

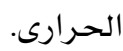
كما أن مصطلح المواطنة البيئية ليس واسع الانتشار، لأنه لا يزال من المفاهيم الوليدة حيث ظهرت العديد من المفاهيم ذات العلاقة بالمواطنة والبيئة، ومنها المواطنة الايكولوجية Eobson \& Ecological Citizenship 
وحده وإنما مسئوولية مؤسسات المجتهمع كله مِ حِين

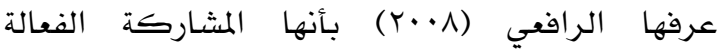
للهواطنين بِّ التوجه نحو الاستدامة، وهي تتحدى المفاهيم التقليدية للمواطنة لتعكس طبيعة المشكلات البيئية، وهي جزء أسـاسي من تغيير الاتجاه نحو الحكم الرشيد للسياسة البيئية والقائمـين على وضع هذه السياسـة، بينهاعرفها (حنفي، • · ) بأنها ذلك الإحساس بالبيئة المحيطة والناتج عن معرفة التلميذ بهشكلات بيئته وقدرته على المثاركة وِّور طرح أساليب حله، والمشـاركة ِوْ اتخاذ قرارات إيجابية نحو البيئة، من خلال إدراكه لحقوقه وواجباته تجاه بيئته مها يؤدي إلى الانتهاء للبيئة التي يحيا فيها وينعمر بهواردها المتعددة، شريطة أن ينجم عن هذا الانتهاء المشاركة

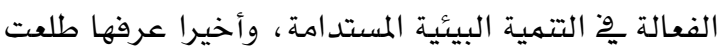
(Y) بأنها وعي التلميذ بالقضايا البيئية المحلية والعالمية (مسئوليته الشخصية) متفهما لشئونها متحفزا لصون بيئته ويعرف حقوقه وواجباته البيئية مها يدفعه للمشاركة ِّ2 العهل الجماعي التعاوني لمواجهة المشكلات البيئية، وبالتالى نجد أن المواطنة البيئية تتضهن علاقة جديدة بين المواطن والبيئة باعتبارها موطنا لله وذلك لمواجهة مشكلات البيئة؛ تقوم هذه العلاقة على المسـاواة، والعدالة بين المواطنين، والعهل معا نحو استدامة الموارد والتأكيد على الحقوق البيئية للمواطن والمسئولية الفردية والجماعية البيئية والمشاركة فى اتخاذ القرار، وتقديم آليات لتحقيق المجتمع المستدام. وفى هذا الصدد أشـار ناريان (ع · ب) إلى صفات الأفراد الـذين يتســمون بالمواطنـة البيئيـة بـأنهم مـواطنـين يتحلـون بالمســئولية ، مــدركين لحقــوقهم وواجبــاتهم البيئيــة ، يمتلكـون مهـارات المشــاركة والقيـام بأنشـــة إيجابيـة ولهم دور إيجابي يُّ مجتمعاتهم وبِّ العالم ككل.

هذا وقد حددت رابطة أمريكا الشهالية للتربية البيئية (North American Association of Environmental مبادئ توجيهية أساسية للمواطنة Education, 2006) البيئية تمثلت فى اتخاذ اتجاهات (مواقف) بشـأن قضية بيئية، الاعتراف بوجهات النظر الثقافية المتتوعة عن البشر والبيئة، تحليل العواقب البيئية لتصرفات
منظومة المحيط الحيوي: التي تتضهن المككونات الحية وغير الحية ِّْ البيئة (من ماء وهواء وترية وموارد أخرى)، وهو يحصل على حقوقه من هذه الموارد وعليه واجبات ينبغي أن وندون يلتزم بها نحو المحافظة عليها وحمايتها بالمشاركة مع غيره من المواطنين ِِّ الوطن

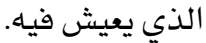

منظومة المحيط الاجتماعي: التي تتضهن

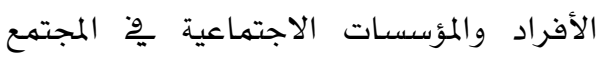
والتي يتفاعل معها بشكل يوهي وتتطبق عليها

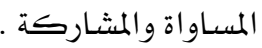

منظومة المحيط المصنوع: التي تتضمن كل ما صنعه الإنسان من آلات وأجهزة والتى أدت إلى ظهور العديد من المشكلات البيئية ومن ثم تتطلب إيجاد الحلول المناسبة لها.( الرافعي،

$$
(Y \cdots \wedge
$$

وقد تعددت مفاهيم المواطنة البيئية حيث عرفها (غندور، 0 · بأنها السلوك الذي ينتهجه الفرد لحماية البيئة المحلية والعالمية ومواردها الطبيعية وصونها من التلوث، مها يعكس معرفة ووعيا بندرة الموارد الطبيعية من جهة، ومحدودية قدرتها على التجدد أو إعادة التأهيل الذاتي من جهة أخرى، وأهمية المحافظة عليها وتتميتها باستدامة، بينما عرفها (Derek \& Bell , 2005) بأنها الالتزام الشخصي لسكان كوكب الأرض لتعلم المزيد عن البيئة وحمايتها ، وإجراء أفعال إيجابية لصالح البيئة باستمرار، وتثتيع الأفراد والجماعات والمنظمات للتفكير يِّ الحقوق والمسئوليات البيئية، في حين عرفها "بأنها المشاركة الفعالة (Dobson \& Derek, 2005) للمواطنـين ِّْ التحرك نحو تحقيق الاستدامة ومواجهة التحديات التقليدية التي تعكس طبيعة المشكلات البيئية، بينما عرفها (Juilie et al, 2005) بأنها تصرف الفرد المسئول والإيجابي نحو البيئة يٌْ مجتهع عادل يوفر السبل لتعزيز الاستدامة والعدالة البيئية، وعرفها أبا

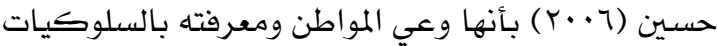
البئية الإيجابية التي يجب أن يتبعها ويؤمن بأن عليه واجبات تجاه بيئته، وأن هذه الواجبات ليست مسئووليته 


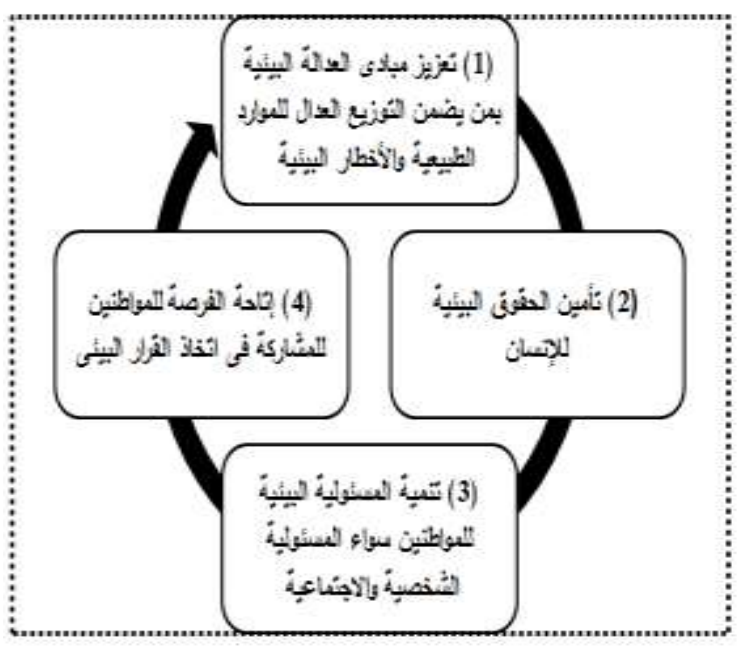

شكل ا أهداف المواطنة البيئية

(Y.1) أبعاد المواطنة: المسئولية الشخصية البيئية والعـــالة البيـــئية والعهل الجماعي التعاوني البيئي، بينها حدد (السـاعدى، ع|+r) أبعاد المواطنة في أربعة أبعاد تمثلت فى: المسئولية الثخصية البيئية و العــدالة البيــئية والمشناركة البيئية والاخلاقيات البيئية وأخيرا حدد (عطية ، ع ا †) أبعاد المواطنة فى أربعة أبعاد تمثلت فى: السلوك البيئي المسئول، الاتجاه نحو تحقيق العدالة البيئية ، المشاركة يخ حل مشكلات البيئة ، الإتجاه نحو التتمية المستدامة.

وتتعدد وسائل تتمية المواطنة البيئية ومنها الأسرة ودور العبادة والمؤسسات التعليمية والتربوية ووسـائل الإعلام وجمعيات النفع العام ( الحسينى، (1) • (Y). وقد تتاولت العديد من الدراسات دور التربية فى تتمية المواطنة البيئية ومنها دراسة (Hungerford, 1996) والتى ملى أشارت إلى أن تتمية المواطنة البيئية تعد تحديا حاسما ،

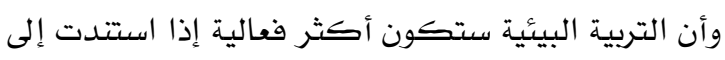
متغيرات سلوك المواطنة البيئية سـواء المستويات الخارجية Ewnership أو المستويات الذاتية Entry-Level يتضح من خلال شكل r.
الشركات أو المجتهـع، شرح القضايا البيئية الحالية والتاريخية من حيث الأفكار السياسية والاقتصادية، تقييم الآثار التراكمية لتصرفات البشر تجاه النظم البيئية، شرح أهمية المكان المناسب للإنسان وتحديد الروابط بين قضايا المواطن والبيئة ، ومنها على سبيل المثال، العلاقات بين الاختتاقات المرورية، وسـوء جودة

$$
\text { الهواء، والزحف العهراني. }
$$

فى حين وضع برنامج الأمم المتحدة للبيئة لدول غرب آسيا أهداف المواطنة البيئية فيها يلى: إكسـاب المواطنين المهارات والمعلومات التي تسـاهم مِّ الإصلاح البيئي من أجل التتمية المستدامة ، تحسيـين السلوك البيئي فِ الحياة العامة، السعي إلى تجنب الأضرار البيئية قبل وقوعها ، والمطالبة بإثبات عدم وجود أضرار بعيدة المدى للأنشطة البيئية المقترحة، الإسهام وِّ رفع مستوى المعرفة والثقافة البيئية العامة للأفراد لتحفيزهم على المشاركة ِِّ اتخاذ القرارات، ووضع الحلول المعنية بالشئون البيئية والتتموية وأخيرا تبادل الخبرات بين المنظمات الحكومية وغير الحكومية وبين اللجنة الخاصة ببرنامج المواطنة البيئية التابع لبرنامج الأمه المتحدة للبيئة لدول غرب آسيا.

(United Nations Environment Programme, 2004) بينهـا أشـار كـل مـن (Andrew \& Derek, 2005) إلى أهداف المواطنـة البيئيسة بأنها تتحـدد في وصف علاقـات سياسـية جديـدة بـين المـواطنين والـوطن بِّ المســائل الـتي

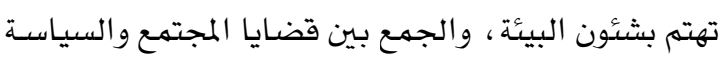
والبيئة لتحقيـق مجتهـع أكثتر اسـتدامة ، وتأصسيل مبـدأ المواطن الرشيد الذي يراعي الاهتمامات البيئيـة وشئونها و تحقيـق الشــراكة بـين الحكـومــة والمــواطنـين لتحقيـق الاستدامـة ، مها سبق فإن الباحثة حددت أهداف المواطنة البيئية من وجهه نظرها كها يتضح من شكل 1. وتتعدد أبعاد المواطنة البيئية حيث حدد (الحسينى، • • ثلاثة أبعاد للمواطنة البيئية وهى: المسئولية الشخصية البيئية/ العدالة البيئية (الحقوق -الواجبات)

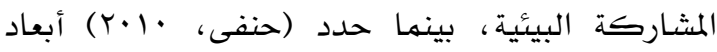
المواطنة فى المعارف البيئية-مهارات التصرف فى المواقف لئفئ البيئية- والاتجاه نحو البيئة ، في حين حدد (طلعت، 


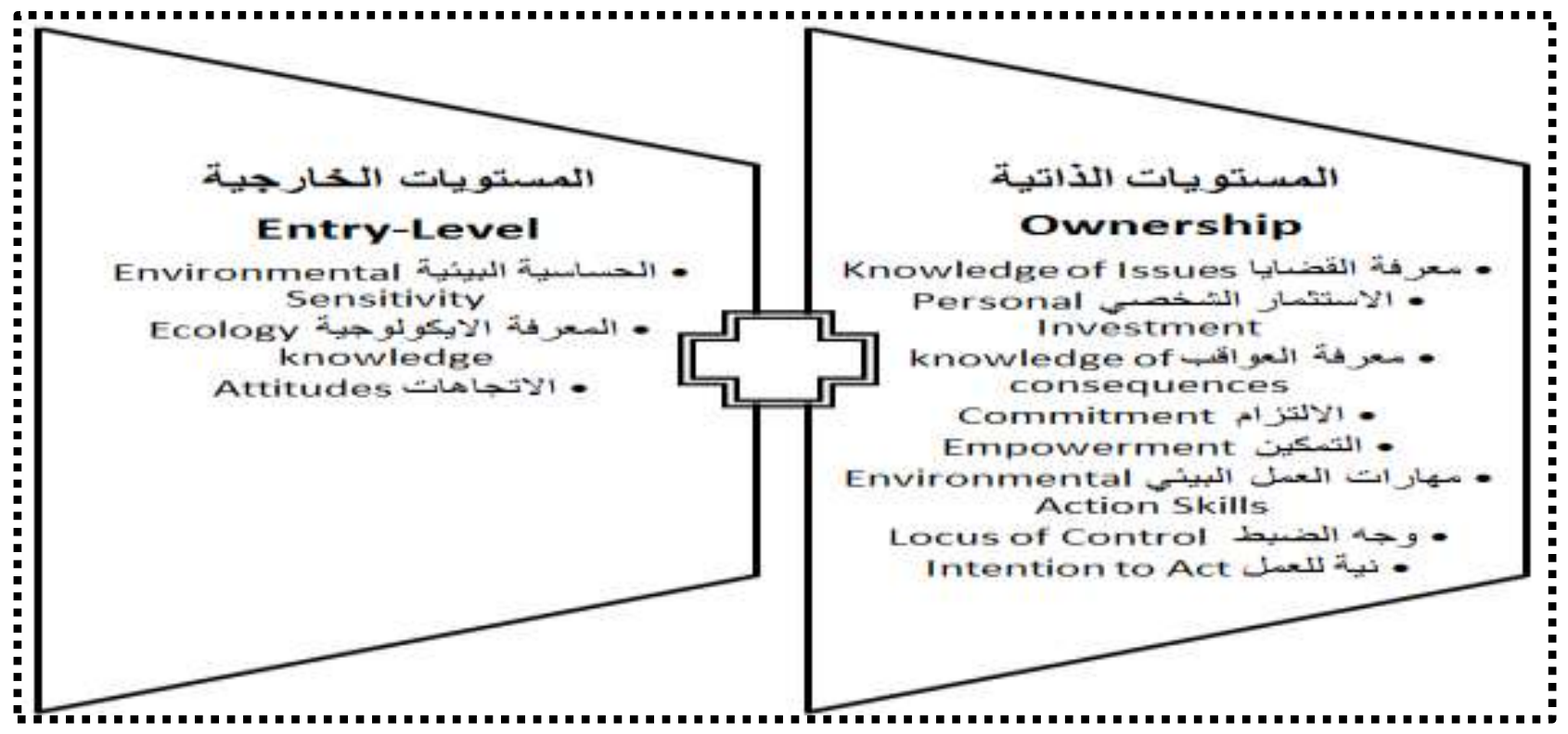

شكل r متغيرات سلوك المواطنة البيئية

تدريبه على كيفية اتخاذ قرارات بيئية وتطبيقها ووضع خطة العهل وتوفير فرص مناسبة له لتتفيذ تلك الخطط

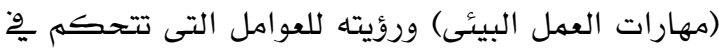
بيئته، ومدى كونها، عوامل داخلية ترتبط باه وهنا يكون من ذوي الضبط الداخلي، أو عوامل خارجية، ترتبط بالصدفة ، أو الحظ أو جهود الأخرين وهنا يكون اون اونون من ذوي الضبط الخارجي( وجه الضبط )، القصد في العمل من خلال المواقف الإيجابية تجاه البيئة لمنع حدوث مشككلات في المستقبل, وإدراك العلاقة بين المعرفة والقصد للمشاركة بفاعلية فى حماية وتحسين البيئة والاستهلاك السليم، والحفاظ على مواردها (نية العمل). أما دراسة (Hungerford \& Volk, 1990) استهدفت تفيير السلوك من خلال مناهـج التربية البيئية وقد أشار الباحثان الى ثلاثة متفيرات أساسية لتفيير السلوك وهى (المستويات الذاتية والمستويات الخارجية والتمكين) حيث تم مراجعة أهداف وغايات التربية البيئية ومن ثم تحديد المككونات الرئيسية لبرنامج تعليهى فى التربية البيئية وتحديد الاستراتيجيات المناسبة لتحقيق أهداف البرنامج وتم وضع بعض نماذج العمل للتحقيق فى القضايا البيئية؛ وقد أشارت الدراسة إلى ستة عناصر أساسية تهكن المعلمين من تحقيق أقصى درجة من التغير السلوكي عند دمجها بِِّ بيئة التعلم وهى:
حيث تشير المستويات الخارجية إلى (مؤشرات للتتبؤ بسلوك المواطنة المسؤولة ) ومنها أن يكون الفرد أكثر حساسية للمنتجات المعطرة، ومنتجات التتظيف، منظفات الغسيل، والدهانات، والبتروكيماويات، ودخان السبائر، والمبيدات الحشرية، والحيوانات الأليفة، والإشعاع الكهرومغناطيسي، والمواد الحافظة الحساسية البيئية)، وأن يمتلك العديد من المعارف المرتبطة بعلاقة الكائن ببيئته الطبيعية بها يساهم في اتخاذ قرارات بيئية سليمة (المعرفة الايكولوجية)، ولديه اتجاهات بيئية ايجابية نحو البيئة (الاتجاهات)، بينها تشير المستويات الذاتية إلى (الملكية الثخصية المرتبطة بالفرد) والتى تتمثل فى حقه فى معرفه القضايا البيئية (معرفة القضايا)، تبنى أنماط الاستتمار المسؤول اجتهاعيا هن خلال الشركات التي تدعم المنتجات والممارسات الصديقة للبيئة ومنها الشركات التى تعتمد على التكنولوجيات الجديدة التي تدعم الانتقال من الاعتماد الكربون إلى بدائل أكثر استدامة (الاستثمار الشخصى)، والتفكير جيدا قبل اتخاذ أى سلوك من شـأنه التأثير على البيئة حتى يسله من النوائب (معرفة العواقب)، والتمسك بقيم المواطنة البئية و إلزام النفس بها ( الالتزام )، إعطاء مزيد من المسؤولية وسلطة اتخاذ القرار البيئى بدرجة أكبر ( التمكين)، 
البيئية لدى الطلاب يرجع إلى تدنى مستوى المعرفة البيئية، وأن البرامج التعليمية التى تقدم للطلاب تساهم فى تتمية المواطنة البيئية لديهم. واستهدفت دراسة (Skye, 2004) التعرف على خصائص برامج الكبار والتربية البيئية فى مراكز التربية البيئية من خلال برامج المواطنة البيئية للبالغين، والتى يتم تقديهها عن طريق المفوضية الأوروبية، وقد أوضحت الدراسة سبع عقبات تحول دون تقديم برامج تتضهن فى

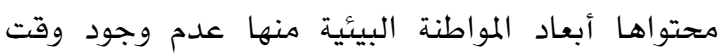
كاف لدمج الجوانب النظرية مع الممارسة . أما دراسة (MacPherson, 2005) استهدفت تربية المواطنة من خلال برنامج متعدد التخصصات قائم على مبادئ الايكولوجيا والأفكار الليبرالية والقيم والأخلاق الإيكولوجية، وتطوير صياغة نظام المجتمع من نظام

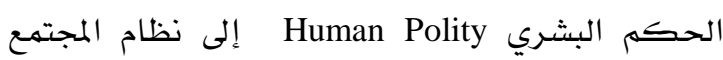

الحيوى Biotic Community.

بينما تتاولت دراسـة (Seyfang, 2006) العلاقة بين المواطنة البيئية والاستهلاك المستدام وقد أشار الباحث الى أن الاستهالك المستدام يعد هدف من أهداف السياسات البيئية الجديدة وكيف يهكن أن تكون المواطنة البيئية قوة دافعة للسلوك الاستهلاكى المستدام، كما تناول الباحث النظريات الخضراء (نظريات الاقتصاد الجديد).

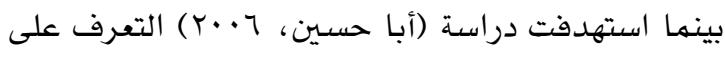
مؤشرات تحقيق المواطنة البيئية، وتسليط الضوء على مفهوم المواطنة البيئية وبيان دور المواطن تجاه قضايا

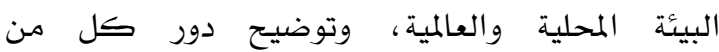
الحكومات وجمعيات المجتمع المدنى، والمواطن فى بناء هذا المفهوم وتعزيزه، وقد توصلت الدراسة إلى أهمية تتمية مستوى وعى المواطن بالمشكلات والتحديات البيئية وتعزيز مشاركته فى الرقابة البيئية واتخاذ القرارات هما ينمى ارتباط المواطن ببيئته ويعزز شعوره بإمكانية المشاركة في إدارتها والمحافظة عليها و تحديث مناهج التعليم وما تتضمنها من قضايا بيئية والقوانين والتشتريعات البيئية بها يتواءم مع المتفيرات على الصعيد المحلى والعالمى، وإتاحة الفرصة للمشاركة فى
ا. تدريس المفاهيم البيئية الهامة وتوضيح العلاقات بين هذه المفاهيم.

Y. تصميم فرص للمتعلمـين لتحقيق مستوى هن

الحساسية البيئية من شأنها تعزيز الرغبة ِون التصرف بطرق مناسبة.

r. توفير المناهج الدراسية بها يساهم فى تتمية معرفة أعمق للقضايا البيئية.

ع. توفير المناهج الدراسية بها يساهم فى تتمية مهارات الطلاب على التحقيق فى القضايا البيئية

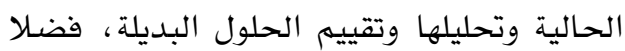
عن توفير الوقت اللازم لتطبيق هذه المهارات فى الصف.

0. توفير المناهـج الدراسية بها يساهم فى تعزيز مهارات المواطنة اللازمة لمعالجة القضية فضلا لماكيل عن توفير الوقت اللازم لتطبيق هذه المهارات فى الصف. 7. توفير بيئة تعليمية تتيح للطالب اتخاذ السلوك

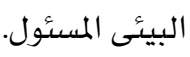

فى حين استهدفت دراسة (Lewis, 1998) إعداد كتيب عن المواطنة البئية للشباب وقدم فيه الباحث معلومات لتتمية السلوك البيئى المسئول سواء فى المنزل أو المدرسة، وحدد سمات المواطن البيئى والذى يتصرف بطرق لا تضر بالبيئة ويهتلك القدرة على فهم أن الانسان جزء لا يتجزاً من البيئة ، ثم تتاول طرق ترشيد الكهرباء والمياه بالمنزل، والحفاظ على الهواء الطلق من خلال زراعة الأشجار المحلية وتحويلها إلى سماد والأشجار المحلية، ونوعية المياه ِِّ البيئة، والحفاظ على المدرسة وتتمية مستوى الوعي البيئي لدى البالغين، وإعادة التدوير يُ2 المنزل والمدرسة، وأهمية إعادة التدوير وشراء

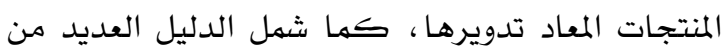
الألعاب والمسـابقات والألغاز.

أما دراسـة (King, 2004) استهدفت التعرف على المواطنة البيئية لدى الطلاب من المرحلة الابتدائية حتى المرحلة الجامعية، والدوافع والقيود التى تؤثر على التزامهم نحوها، وقد توصلت الدراسة إلى أن ضعف المسئولية 
المواطنة البيئية لدى تلاميذ المرحلة المتوسطة فى دولة الكويت.

فى حين استهدفت دراسة (حنفى، · · (Y) تتمية مهارات المواطنة البيئية لدى تلاميذ الصف الأول الإعدادى بالمرحلة الإعدادية ، وذلك من خلال إعداد منهج مطور في العلوم قائم على الاستقصاء، وحل المشكلات، وقد اشتملت أدوات الدراسة على مقياس المواطنة البيئية والذى تكون من اختبار المعارف البيئية ، مقياس مهارات التصرف فى المواقف البيئية، ومقياس الاتجاه نحو

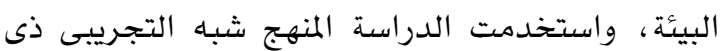
المجموعتين حيث اقتصرت الدراسة على وحدة مقترحة من المنهج المطور " وحدة إدارة المخاطر البيئية " وشملت هجموعة الدراسة وجع تلميذا من تلاميذ الصف الأول الإعدادى بهدرسة الرشاد بإدارة المطرية التعليمية وأسفرت النتائج عن فاعلية الوحدة المقترحة "وحدة إدارة المخاطر البيئية" فى تتمية مهارات المواطنة البيئية لدى تلاميذ الصف الأول الإعدادى.

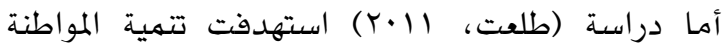
البيئية لدى تلاميذ المرحلة الإعدادية وذلك من خلال برنامج مقترح قائم على استراتيجية التعلم التعاونى، حيث تم التطبيق على مجموعة من تلاميذ الصف الأول الإعدادى بمدرستى الزيتون الإعدادية بنين، الزيتون

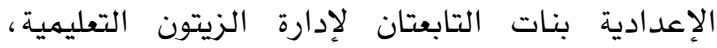
واستخدم الباحث المنهج شبه التجريبى وقد أشارت نتائج الدراسة إلى وجود فرق دال إحصائيا عند مستوى 0•. فى متوسط درجات التلاميذ لأبعاد المواطنة البيئية (المسئولية الشخصية البيئية / العدالة البيئية / العمل الاجتماعى التعاونى البيئى) قبل وبعد تطبيق البرنامج لصالح التطبيق البعدى. فى حين أستهدفت دراسة (على، (|lY) تتمية القيم البيئية لدى طلاب المرحلة الإعدادية من خلال تدريس وحدة مقترحة قائمة على المواطنة البيئية بهقرر الدراسـات الاجتماعية، وقد تم استخدام المنهج التجريبى وقد اشتملت مجموعة الدراسة على مجموعتين من الطلاب (مجموعة ضابطة وآخرى تجريبية) بإدارة الزيتون التعليمية، وقد أشارت النتائج إلى وجود فروق دالة
اتخاذ القرار والشفافية فى التعامل مع البيانات والمعلومات الخاصة بحالة البيئة.

في حين تتاولت دراسة (Kushmerick et al, 2007) تحليل محتوى العدالة البيئية ِِّْ مراحل التعليم المختلفة بداية من الصف السـادس حتى الصف الثانى عشر باعتبار العدالة البيئية أحد أبعاد المواطنة البيئية، حيث أشـارت الدراسـة إلى أنه على مدار العقود الثلاثة الماضية شهدت حركة العدالة البيئية قلق متزايد بشأن التوزيع غير المتكافئ للضرر البيئي وعدم المساواة ِِخ الحصول على الموارد البيئية، وانتقدت الحركة البيئية السائدة لفشلها ِوْ معالجة قضايا العدالة البيئية على نحو كاف، بالإضافة إلى قصور دور التربية البيئية فى دمج مفاهيم العدالة البيئية، وقد تم استعراض عبr درس وتقييهها على أسـاس بعض مؤشرات العدالة البيئية، وأشارت النتائج إلى أن أدلة المناهـج الدراسية عالجت بعض القضايا المتعلقة بالعدالة البيئية (مثل الآثار الصحية البيئية على البشر)؛ ومع ذلك، فإنها نادرا ما يتهم عرض القضايا ضهن سياق واضتح لفكرة العدل البيئي، وأن هناك العديد من الفرص المتعددة لدمج العدالة البيئية بالمناهـج الدراسية ، ودراسة (Weilbacher, 2009) والتى أشـارت إلى أن غاية التربية البيئية تتمثل فى تتمية المواطنة البيئية لدى الأفراد من أجل حل المشككلات البيئية ، تلك المشكلات التى أصبحت اليوم أكثر تعقيدا وإلحاحا من أى وقت آخر، ولهم تحقق المدارس التحدى الأكبر لمواجهة تلك المشكلات والمتمثل فى إعداد الشباب لاتخاذ القرارات السليمة حول هذه المشكلات .

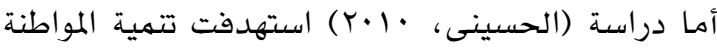
البيئية لدى تلاميذ المرحلة المتوسطة فى دولة الكويت، وذلك من خلال إعداد تصور لتطوير منظومة الإعلام المدرسى، وقد اشتملت أدوات الدراسة على مقياس

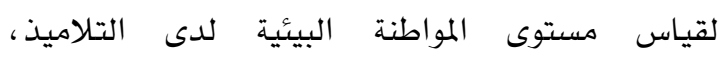
واستخدمت الدراسة المنهج المستحى التحليلى والمنهج شبه

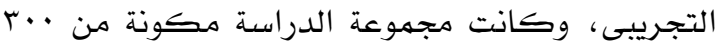
تلميذ وتلميذة من المرحلة المتوسطة ببعض مدارس منطقة العاصمة التعليمية، وأسفرت نتائج الدراسـة إلى فاعلية التصور المقترح لمنظومة الإعلام المدرسى فى تتمية 
الاتفاق عليها فى قمة جوهانسبرج r.r. وتم إضافة Coastal and Marine موضوع الموارد الساحلية والبحرية بالإضـافة إلى تلك الموضوعات، ومن أجل تحقيق هدف الدراسة قام الباحثون بإعداد استبانة لقياس المواطنة البيئية لدى الطلاب واستبانة لاستطلاع رأى المعلمات حول مدى تضهـين المقررات بهوضوعات الوهابك ووحدة إثرائية الكترونية فى المواطنة البيئية، وقد شملت مجموعة الدراسـة (rV) معلمة من معلمات مدرسة طرفه بن العبد الإبتدائية بنين، (77) طالبا تم قياس المواطنة

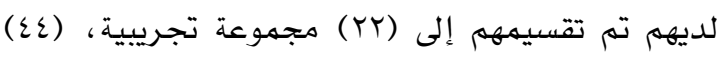
مجموعة ضابطة وقد أشارت النتائج إلى فاعلية الوحدة الإثرائية الإلكترونية فى تتمية المواطنة البيئية لدى المجموعة التجريبية، من خلال عرض الدراسـات السابقة يتضح أن العديد من الدراسات أكدت على ضرروة أن تتضمن المناهـج الدراسية المشكاتلات البيئية التى تساهم فى تتمية المواطنة البيئية مثل دراسة (المجادى، 1999;

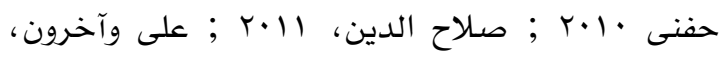
10) ، وله يقتصر أهمية تتمية المواطنة البيئية بالمراحل التعليمية المختلفة بل امتدت الى أهمية تتمية المواطنة البيئية من خلال برامج تعليم الكبار وهو ما جاء فى دراسة (Skye, 2004) أو المؤسسات غير النظامية

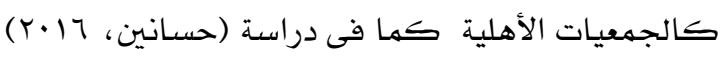
أو الإعلام المدرسى كما جاء فى دراسـة ( الحسينى،

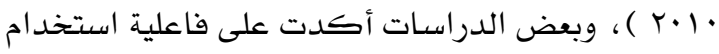
استراتيجيات متتوعة لتتمية المواطنة البيئية مثل مل ماتل استراتيجية التعليم التعاونى كما جاء فى دراسة

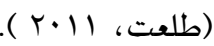

\section{مشكلة الدراسة}

أشار المؤتهر الدولي حول طبيعة تدريس الدراسات والعلوم البيئية يخ التعليم العالي المنعقد في انجلترا فى في

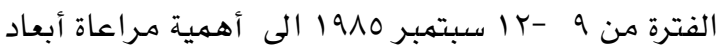
المواطنة البيئية بالمناهـج الدراسية لتشكيل التربية البيئية الحديث، كها أشـارت دراسة المجادي (1999) إلى ضرورة تتاول المشكلات والقضايا المعاصرة بالمناهـج الدراسية التي ستسـاهم وِ تتمية المواطنة والوعي البيئي والاهتمام بالدراسـات والبحوث التربوية المتعلقة بالمواطنة
إحصائيا بين متوسطى المجموعتين الضابطة والتجريبية فى القياس البعدى لكل من الاختبار التحصيلى ومقياس قيم المواطنة البيئية لدى طلاب المرحلة الإعدادية لصالح المجموعة التجريبية.

بينها استهدفت دراسة Tarrant \& Lyons 2012) التعرف على دور المنح الدراسية قصيرة الأجل فى تتمية المواطنة البيئية لدى الطلاب حيث شملت الدراسة أكثر

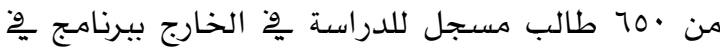
التتمية المستدامة بكل من أستراليا ونيوزيلندا، وأشارت

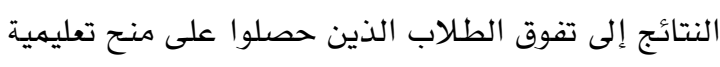
سابقة عن أقرانهم في مجال المواطنة البيئية، ووجود فروق ذات دلالة احصائية بين الذكور والإناث فى تحصيل البرناهـج لصالح الذكور، وأشـارت الدراسة الى أهمية تقديم المنح الدراسية فى مجال التربية البيئية لتتمية المواطنة البيئية.

بينما استهدفت دراسـة (حسانين، 17 17) تتهية المواطنة البيئية لدى أعضاء الجمعيات الأهلية، وذلك من خلال برنامج مقترح قائم على أنشطة الاتصال المباشر وغير المباشر وقد قام الباحث بإعداد مقياس للمواطنة البيئية اشتهل على خهسة مكونات ( الوعى بهفهوم المواطنة

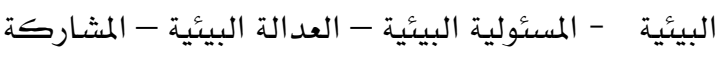
البيئية - التتمية المستدامة البيئية ) تم تطبيقه قبل تدريس محتوى البرنامج وبعديا على ·r عضوا من أعضاء الجمعيات الأهلية، وقد أشارت النتائج إلى فاعلية البرنامج المقترح فى تتمية المواطنة البيئية . وأخيرا استهدفت دراسة (على وآخرون، 10 أب) التعرف على أثر تصميم وحدة تعليمية الكترونية إثرائية عن المواطنة البيئية ومواضيع الوهابك وقياس أثره على المخرجات التعليمية لدى طلاب المرحلة الابتدائية فى دولة الكويت، من أجل ذلك قام الباحثون باستخدام منهج تطوير المنظومات التعليمية مهثلا فى خطوات نهوذج كيمب لتصميم وحدة إثرائية عن المواطنة البيئية وموضوعات الوهابك تمثلت تلك الموضوعات فى (المياة

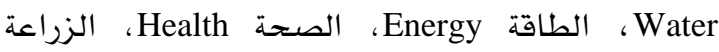
Agriculture ، التوع الحيوى Biodiversity) حيث تمثل أهم التحديات التى تواجه العاله فى الألفية والتى تم 
تتتاول أبعاد المواطنة البيئية.

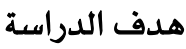

التعرف على تصورات أعضاء هيئة التدريس بجامعة عين شهس حول أبعاد المواطنة البيئية .

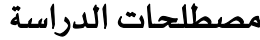

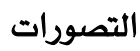

عرفتها الباحثة إجرائيا بأنها "معتقدات أعضاء هيئة التدريس بجامعة عين شمس حول مسئوليتهم وواجباتهم لحماية البيئة وصيانتها، والمشاركة في اتخاذ قرارات لصالح البيئة فى إطار التزام الوطن بتأمين الحقوق البيئية والعدالة فى توزيع الموارد الطبيعية والأخطار

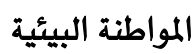

عرفتها الباحثة إجرائيا بأنها "الالتزام الشخصي لعضو هيئة التدريس بجامعة عين شهس لمعرفة المزيد عن البيئة وتحمل مسؤوليته للعمل البيئي ومشاركة الأفراد والمجتمعات المحلية والمنظمات لاتخاذ قرارات بيئية سليمة والمساهمة بِّ2 تحقيق مجتهع عادل وتوفير السبل لتعزيز مفاهيم الحقوق والعدالة البيئية". الطريقة والاجراءات

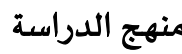
اعتهدت الدراسة الحالية على استخدام المنهج الوصفي للتعرف على تصورات عضو هيئة التدريس بجامعة عين شمس حول أبعاد المواطنة البيئية ثم تحليل البيانات التي تم جمعها وذلك للإجابة عن أسئلة البحث .

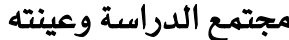

تكون مجتمع الدراسة من جميع أعضاء هيئة التدريس بجامعة عين شهس وذلك خلال الفصل الدراسى للعام الدراسى ع ا•Y - - 10 أما مجموعة الدراسة فتكونت من (YTM) عضو هيئة تدريس بكليات الهندسة،

الصيدلة، الآداب والتربية بجامعة عين شهس بجامعة لهن ويوضح جدول ا توزيع مجموعة الدراسة أساس المتغيرات

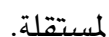

البيئية، وتشجيع الباحثين على العمل ِِّ هذا المجال،

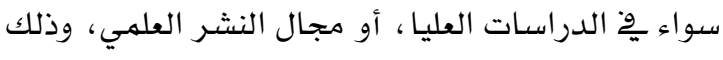
بإعطاء الأولوية ِِّْ نشر هذه البحوث وعقد مؤتمرات

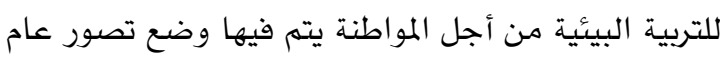
لجوانب المواطنة البيئية، من أجل ذلك قامت الباحثة بدراسة استطلاعية قامت من خلالها بتوجيه الاستبانة لعدد (عץ) عضو من أعضاء هيئة التدريس بجامعة عين شمس اشتمل الاستبانة على خمسة أسئلة حول المواطنة

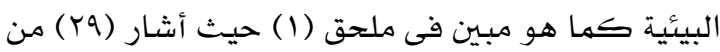
أعضاء هيئة التدريس أنهم على وعى بهفهوم المواطنة بصفة عامة أما المواطنة البيئية فهو مصطلح جديد ، بينما

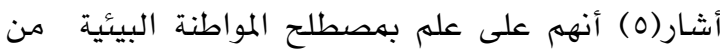
خلال كلياتهم، كما أشار (·) إلى أن المواطنة البيئية

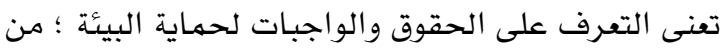
أجل ذلك سعت الباحثة إلى التعرف على مدى تأثير الدرجة العلمية لعضو هيئة التدريس أو النوع أو الكلية على تصوراتهم عن المواطنة البيئية وأبعادها .

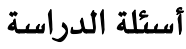

ا. ما أبعاد المواطنة البيئية التى ينبغى أن يدركها أعضاء هيئة التدريس بجامعة عين شمس؟ Y. ما درجة تصور أعضاء هيئة التدريس بجامعة عين

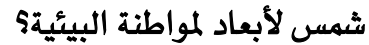

r. هل تختلف درجة تصور أعضاء هيئة التدريس

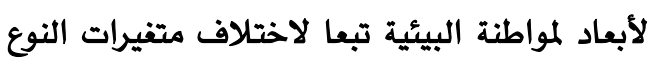

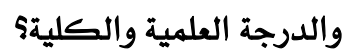

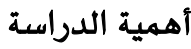

تلبية توصيات العديد من الدراسات العربية و الأجنبية والتي أكدت على أهمية التعرف على التى الترات التربية تصورات المواطنة البيئية وأهمية تتميتها من الهمين التعنيا خلال مراحل التعليم المختلفة. تقديم قائمة بأبعاد المواطنة البيئية يمكن أن

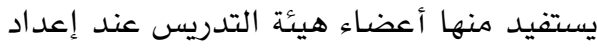
برامج فى مجال التربية البيئية. قد يفتح المجال لإجراء بحوث ودراسات أخرى 
تضمن اب مفردة، البعد الثالث: المسئولية البيئية وتضهن 17 مفردة أما البعد الرابع: المشاركة فى اتخاذ القرار تضمن با مفردة.

عرض القائمة فى صورتها المبدئية على خهسـة خبراء فى مجالى التربية البيئية والمناهـج وطرق تدريس.

حيث تم تعديل أربع مفردات وهى المساواة بين الأجيال الحالية والمستقبلية فى برامج التوعية البيئية بدلا من المساواة بين الأجيال الحالية والمستقبلية فى التثقيف البيئى، والحق فى لئ الحصول على المعلومات البيئية بدلا من الحصول على المعلومات البيئية التي پِّ حوزة السلطات العامة، ومعرفة الفترة الزمنية لكل مرحلة من مراحل اتخاذ القرار بدلا من معرفة المواعيد

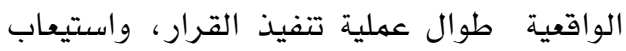
التغيرات الطارئة، والقيود البرنامجية مثل الوقت وترتيبات الاجتماعات عند اتخاذ القرار بدلا من أن تتسم عملية اتخاذ القرار بالمرونة وذلك لاستيعاب القضايا المتغيرة، والقيود البرنامجية مثل الوقت وترتيبات الاجتماعات، وحذف أربع مفردات وهى مفردة الالتزام بتتهية الموارد المتوفرة بالبيئة للأجيال القادمة من بعد العدالـــة البيئيــة وثلات مفردات من بعد المسئولية البيئية وهى توعية الزملاء بالتخطيط العمرانى السليم فى بناء المدارس والمساكن والمستشفيات

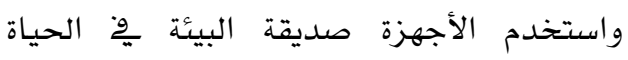
اليومية وغرس روح العهل الجماعي والاهتهام بالبيئة. وضع الصورة النهائية للقائمة.

للاجابة عن السؤال الثانى قامت الباحثة باعداد استبانة لتحديد درجة تصور أعضاء هيئة التدريس لأبعاد لمواطنة البيئية وفقا للاجراءات التالية:

الهدف من الاستبانة: التعرف على تصورات أعضاء هيئة التدريس بجامعة عين شمس عن أبعاد المواطنة البيئية. الصورة الأولية للاستبانة: تكونت الاستبانة من قسهـين،
جدول 1

توزيع مجموعة الاراسة أساس المتغيرات المستقلة

\begin{tabular}{|c|c|c|c|c|c|}
\hline \multirow[t]{3}{*}{ المجموع } & \multicolumn{2}{|c|}{ كليات ( نظرية) } & \multicolumn{2}{|c|}{ ( كليات ( عملية) } & \multirow{2}{*}{ التخصص } \\
\hline & إناث & ذكور & إناث & ذكور & \\
\hline & & & & & العلمية \\
\hline 71 & rr & 19 & 10 & ir & أستاذ \\
\hline VA & $T \varepsilon$ & rt & 19 & $1 \pi$ & أستاذ مساعد \\
\hline IKr & ru & r & rı & ro & مدرس \\
\hline r४A & \multicolumn{2}{|c|}{107} & \multicolumn{2}{|c|}{$11 \mathrm{r}$} & المجموع \\
\hline
\end{tabular}

استبانة للتعرف على تصورات أعضاء هيئة التدريس بجامعة عين شمس حول أبعاد المواطنة البيئية.

الأساليب الإحصائية

معادلة سيبرمان بروان لحساب معامل الإرتباط بين التطبيقين الأول والثاني للاستبانة.

المتوسطات والانحرافات لحساب تصورات أعضاء هيئة

التدريس بجامعة عين شهس حول أبعاد المواطنة البيئية.

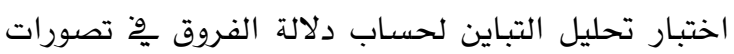
أعضاء هيئة التدريس بجامعة عين شمس حول أبعاد المواطنة البيئية تبعا لمتغيرات ( النوع/ الدرجة العلمية/ الكلية ).

Lest significant Difference (L.S.D) اختبار -

$$
\text { للمقارنة البعدية. }
$$

للاجابة عن السؤال الأول: قامت الباحثة بإعداد قائمة بأبعاد المواطنة البيئية التى ينبغى أن يدركها أعضاء هيئة التدريس بجامعة عين شمس فقا للإجراءات التالية:

تحديد الهدف من القائمة: التعرف على أبعاد المواطنة البيئية التى ينبفى أن يدركها أعضاء هيئة التدريس بجامعة عين شمس. تحديد مصادر اشتقاق القائمة : من خلال مراجعة الأدب التربوي المتعلق بالمواطنة البيئية ومنها دراسات. Dean, 2001; MacGregor, 2006; Dobson \& Smith, 2005; Luque, 2005; Derek, 2005; Dobson \& Bell , 2005).; Juilie Seyfang, 2006). et al,2005 ; Barry, 2006 ;

وضع الصورة المبدئية للقائمة: شملت الصورة المبدئية TV مفردة البعد الأول: العدالة البيئية تضهنVI مفردة، البعد الثانى: الحقوق البيئية 
للاجابة عن السؤال الثالث قامت الباحثة بحساب المتوسطات الحسابية والانحرافات المعيارية، واستخدام تحليل التباين الثلاثى حيث يتم استخدامها عندما يكون

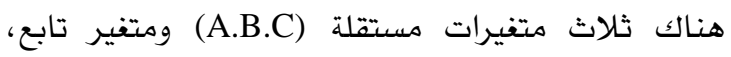
واختبار (L.S.D) للمقارنة البعدية.

\section{النتائج والمناقشّة}

النتائج المتعلقة بالسؤال الأول: نص السؤال الأول على ما أبعاد المواطنة البيئية التى ينبغى أن يدركها أعضاء هيئة التدريس بجامعة عين شمس؟

للإجابة عن هذا السؤال قامت الباحثة بإعداد قائمة للتعرف على أبعاد المواطنة البيئية التى ينبغى أن يدركها أعضاء هيئة التدريس بجامعة عين شمس، وعرضها على الخبراء، ثم تم إجراء التعديلات وشملت الصورة النهائية با7 مفردة البعد الأول: العدالة البيئية تضهن 17 مفردة، البعد الثانى: الحقوق البيئية تضهن اب مفردة، البعد الثالث: المسئولية البيئية وتضمن rا مفردة وأخيرا البعد الرابع: المشناركة فى اتخاذ القرار تضهن سا مفردة. فى ضوء الصورة النهائية للقائمة تم إعداد استمارة استطلاع رأي لعدد ·ل خبراء تضمنت الأبعاد التي تم آمره الاستقرار عليها ، وذلك لإبداء آرائهم حول الأهمية النسبية لأبعاد المواطنة البيئية (مهم/ غير مهم)، مدى مناسبة الأبعاد لأعضاء هيئة التدريس بجامعة عين شمس (مناسب / غير مناسب) و مدي ارتباط المفردة بالبعد

$$
\text { الفرعى (مرتبط/ غير مرتبط). }
$$

تم استخلاص النتائج وتحليلها ومناقشتها: من خلال حسـاب التكرارات الخاصة لاستجابات المحكهمين على مفردات القائمة وحساب النسبة المئوية لأهمية كل مفردة/ ومناسبتها/ وارتباطها بالبعد الفرعى. حيث أشارت النتائج إلى أن الأبعاد الواردة بالقائمة سواء الرئيسية منها أو الفرعية التابعة لها مهمة وذلك بنسبة الى الكا

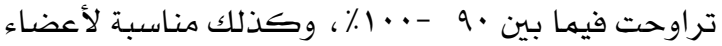
هيئة التدريس بجامعة عين شمس بنسبة تراوحت فيما بين 10 - - 1\%، وأن ارتباط المفردة بالبعد الفرعى تراوحت

$$
\text { بين · - . - }
$$

القسم الأول تضهن هدف الاستبانة وتعليماتها والبيانات الأولية ، والقسم الثاني تم تصميمـه وفقا لمقياس ليكرت الخماسي حيث تضمنسا فقرة تلى كل فقرة خمسـة اختيارات حسب الترتيب الآتي (تصور بدرجة كبيرة جدا، تصور بدرجة كبيرة، تصور بدرجة متوسطة، تصور بدرجة قليلة، تصور بدرجة قليلة جدا) وتم

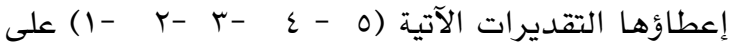
الترتيب وقد تم توزيع الفقرات إلى أربعة أبعاد (العدالة

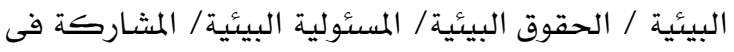

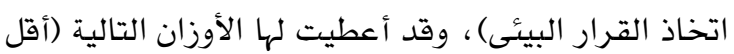

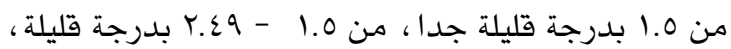

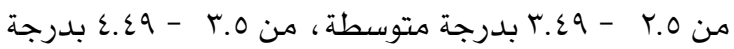
كبيرة ، من 0.ع فيما فوق بدرجة كبيرة جدا ). التحقق من صدق الاستبانة: من خلال عرضها على .

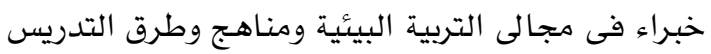
للتأكد من صلاحيتها للهدف الذي أعدت من أجله، وأفاد الخبراء أنها صالحة لذلك.

التحقق من ثبات الاستبانة: من خلال إعادة التطبيق حيث طبقت الاستبانة على عينة هن خارج مجتمع الدراسة مكونه من (•r) عضو من أعضاء هيئة التدريس، ثم أعيد تطبيق الاستبانة مرة أخرى على نفس المجموعة بعد أسبوعين وتم حساب معامل الارتباط باستخدام معادلة سيبرمان بروان فوجد أنها تساوى 10. · كما يتضح من خلال جدول Y، وهذا يشير إلى أن الاستبانة لها درجة عالية من الثبات، وبهذا تكون الباحثة قد استكملت الإجراءات اللازمة للتأكد من صدق الأداة وثباتها، وأصبحت الاستبانة جاهزة للتطبيق.

\section{جدولr}

\begin{tabular}{|c|c|c|c|}
\hline معامل الارتباط & & البعد & الرقم \\
\hline. .AV & & العدالة البيئية & 1 \\
\hline. .19 & & الحقوق البيئية & r \\
\hline .9. & & المسئولية البيئية & $r$ \\
\hline..$\wedge \Lambda$ & اتخاذ & القرار البيئى المشى فى & $\varepsilon$ \\
\hline. .10 & & الاداة ككل & \\
\hline
\end{tabular}

معاملات ثبات الاستبانة 
أظهر التحليل الإحصائي فروقا ذات دلالة إحصائية بين متوسطات استجابات أفراد العينة ِِّ متفيرات( النوع، والدرجة العلمية، والكلية) ولمعرفة مصادر هذه الفروق تم استخدام اختبار (L.S.D) للمقارنة البعدية كها يتضح من خلال جداول ع ، 0 ، 7

\section{درجة تصور أعضاء هيئة التدريس لأبعاد لمواطنة البيئية} تبعا لمتفير النوع ( ذكر/ أنثى)

يتضح من جدول ع وجود فروق ذات دلالة إحصائية عند مستوى دلالة 0•. بين متوسطات استجابات أفراد

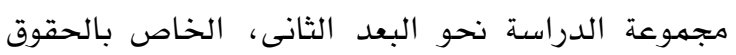
البيئية حيث بلفت قيمة ف 10.r وباستخدام اختبار اتضح مصدر هذه الفروق لصالح الإناث بينها لا توجد فروق ذات دلالة إحصائية عند مستوى دلالة ه•. بين متوسطات استجابات العنية نحو أبعاد المواطنة البيئية حيث بلفت قيمة ف للأبعاد ككل بو. ؟

وقد ترجع هذه النتيجة إلى اهتمام العديد من الدراسات

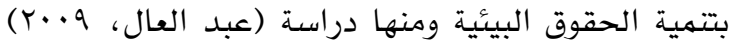
والتى أشارت الى فاعلية الألعاب التعليمية فى تتمية الوعي بالحقوق البيئية للطفل ومهارة اتخاذ القرار لدى

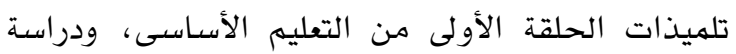

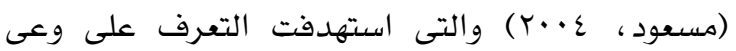
طلاب الحلقة الثانية من التعليم الأسـاسى بالحقوق

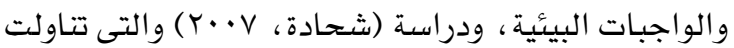
الحق فى الحصول على المعلومات فى مجال البيئة باعتباره حق من الحقوق الأسـاسية للإلسـان، ودراسة ( أمـين، Y Y.Y) والتى استهدفت التعرف على أثر التسعير على ونى

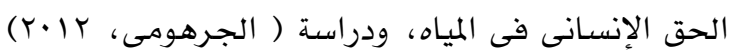
والتى تتاولت حق الإنسان فى التعويض عن الأضرار

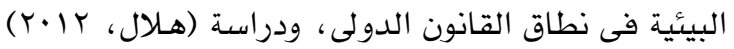
والتى تتاولت الحماية الدولية للبيئة أثناء النزاعات المسلحة، ودراسة (عزوز، 11/ب) والتى استهدفت حق

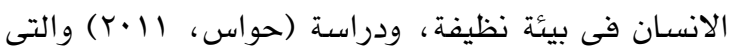
استهدفت حق الانسـان فى التعرف على طرق التعويض عن ولن

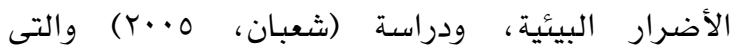
استهدفت التعرف على طرق التعويض عن أضرار البيئة فى محيط الجوار، ودراسة (يوسف، 0 • ب) والتى
النتائج المتعلقة بالسؤال الثانى: ما درجة تصور أعضاء هيئة التدريس لأبعاد المواطنة البيئية؟ للإجابة عن هذا السؤال قامت الباحثة بإعداد استبانة لتحديد درجة تصور أعضاء هيئة التدريس بجامعة عين شمس لأبعاد المواطنة البيئية وقد شملت الاستبانة فى صورتها النهائية أربعة أبعاد. شهل البعد الأول "العدالة البيئية" 17 فقرة والبعد الثانى "الحقوق البيئية" اب فقرة والبعد الثالث "المسئولية

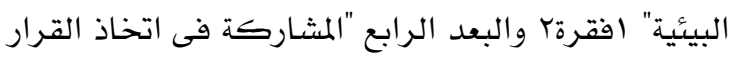
البيئى" سا فقرة. ثم تم حساب المتوسطات الحسابية والانحرافات المعيارية لاستجابات أفراد مجموعة الدراسة على فقرات الأداة المستخدمة وفقا لأبعاد المواطنة البيئية.

جدولr

المتوسطات الحسابية والانحرافات المعيارية لارجة تصور

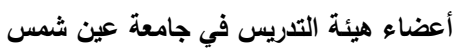
وفقا لأبعاد المواطنة البيئية مرتبة تنازليا

\begin{tabular}{|c|c|c|c|}
\hline التصور & الالتحراف & الحسابى المسط & البعد \\
\hline كبيرة & r.vo & $\varepsilon . \wedge 9$ & الحقوق البيئية \\
\hline كبيرة & r.qr & $\varepsilon . r \varepsilon$ & المسئولية البيئية \\
\hline كبيرة & T.AT & E.YT & التخاذ القرار \\
\hline متوسطة & т.५. & T.rT & العدالة البيئية \\
\hline
\end{tabular}

يتبين من جدول ب أنه يوجد فروق بِ المتوسطات الحسابية لدرجة تصور أعضاء هيئة التدريس بجامعة عين شهس وفقا لأبعاد المواطنة البيئية حيث جاء وِّ المرتبة الأولى بعد الحقوق البيئية وحصل على متوسط حسابي 19.ع ويعكس درجة تصور كبيرة جدا، يليه بعد بعدي المسئولية البيئية وحصل على متوسط حسابي مقداره عَع، ويعكس درجة تصور كبيرة، وجاء ِوْ المرتبة الثالثة بعد المشاركة فى اتخاذ القرار البيئى بهتوسط حسابيجr.\& ويعكس كذلك درجة تصور كبيرة، وأخيرا جاء بعد العدالة البيئية وحصل على متوسط

حسابي مقداره Yr.r، ويعكس درجة تصور متوسطة . النتائج المتعلقة بالسؤال الثَالث :هل تختلف درجة تصور أعضاء هيئة التدريس لأبعاد لمواطنة البيئية تبعا لاختلاف متغيرات النوع والدرجة العلمية والكلية ؟ 
والعرفية التي تتنهك حقوق النساء والأطفال المعوقين، والصحة الإنجابية وحقوق المرأة والشباب والمعوقين، لمانية والحصول على فرص متساوية فى العمل والتعليم، ودراسة (Syed, 2008) والتى استهدفت الكشف عن

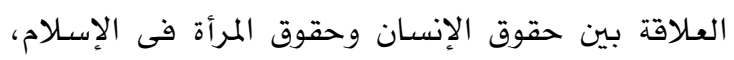

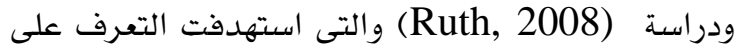
فاعلية برنامج فى مجال تعليم الكبار عن التتوع الديني ومكافحة التمييز وقد أشار الباحث الى أهمية إدراج

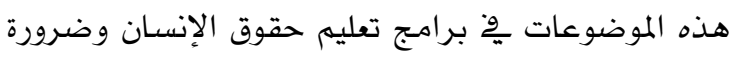

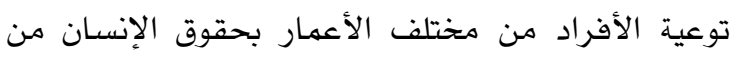
خلال المدارس والجامعات والمؤسسات غير النظامية.

\section{درجة تصور أعضاء هيئة التدريس لأبعاد لمواطنة البيئية تبعا لمتغير الدرجة العلمية}

استهدفت الحقوق الغذائية للمرأة، ودراسة ( عبد العزيز، Y.10) والتى استهدفت توعية طلاب الجامعات بالتشريعات البيئية باعتبارها أحد الحقوق البيئية

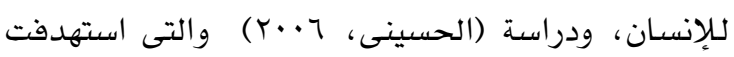

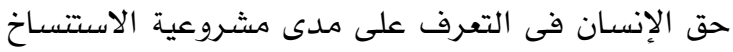
وأثره على التتوع البيولوجى، ودراسة (Chung, 2005) والتى استهدفت توضيح العلاقة بين المرأة وحقوق الإنسان

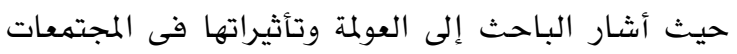

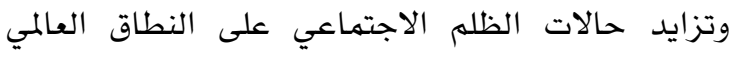
خصوصا للأطفال والنساء وأهمية توعية تلك الفئات بحقوقهم فى الحياة، ودراسة (De Silva, 2008) والتى استهدفت تتمية وعى الأفراد ببعض الحقوق الخاصة بالمساواة بين الجنسين، والحق فى التتمية وعدم التمييز والعنف ضد النساء المعوقات والممارسات التقليدية

جدول ؛

تحليل التباين لاستجابات أعضاء هيئة التدريس لأبعاد المواطنة البيئية تبعا لمتغير النوع (ذكر/ أنثى)

\begin{tabular}{|c|c|c|c|c|c|}
\hline ق ق قيمة ف & متوسط المربعات & درجات الحرية & مجموع المربعات & مصدر التباين & 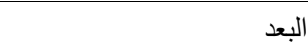 \\
\hline \multirow{2}{*}{ 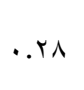 } & $0 . V \varepsilon$ & 1 &. $.1 \mathrm{~V}$ & بين المجموعات & \multirow{2}{*}{ العدالة البيئية } \\
\hline &.$r$. & דצד & $\Sigma 1 . r \mu$ & داخل المجموعات & \\
\hline \multirow{2}{*}{ r.10 } & $1 . r 1$ & 1 & $r .70$ & بين المجموعات & \multirow{2}{*}{ الحقوق البيئية } \\
\hline &. .49 & Tצד & $71.9 \leq$ & داخل المجموعات & \\
\hline \multirow{2}{*}{$.9 \varepsilon$} & 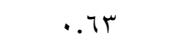 & 1 & 1.7 & بين المجموعات & \multirow{2}{*}{ المسئولية البيئية } \\
\hline & 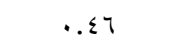 & YฯT & $11 \cdot . \varepsilon \wedge$ & داخل المجموعات & \\
\hline \multirow{2}{*}{$.0 Y$} &.$r u$ & 1 & אד.. & بين الدجموعات & \multirow{2}{*}{ المشاركة فى اتخاذ القرار البيئى } \\
\hline &.$r \varepsilon$ & Tצד & 77.10 & داخل المجموعات & \\
\hline \multirow{2}{*}{.94} & $\vee .9 v$ & 1 & $Y 1.70$ & بين الدجموعات & \multirow[t]{2}{*}{ الإجمالى } \\
\hline & $1 . \wedge \varepsilon$ & Tצד & rrד.IV & داخل المجموعات & \\
\hline
\end{tabular}

جدول

تحليل التباين لاستجابات أعضاء هيئة التدريس لأبعاد المواطنة البيئية تبعا لمتغير الارجة العلمية (مدرس/ أستاذ مساعد/ أستاذ)

\begin{tabular}{|c|c|c|c|c|c|}
\hline فيمة & متوسط المربعات & درجات الحرية & مجموع المربعات & مصدر التباين & البعد \\
\hline \multirow{2}{*}{.90} & .04 & $r$ & $1.7 \pi$ & بين المجموعات & \multirow{2}{*}{ العدالة البيئية } \\
\hline &. .07 & rTo & $11 \cdot . \times 4$ & داخل المجموعات & \\
\hline \multirow{2}{*}{ Y.AV } &..$\wedge 7$ & r & T. ¿ T & بين المجموعات & \multirow{2}{*}{ الحقوق البيئية } \\
\hline & 更 & 197 & תו.וזד & داخل المجموعات & \\
\hline \multirow{2}{*}{$.7 r$} & 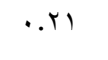 & r & . & بين المجموعات & \multirow{2}{*}{ المسئولية البيئية } \\
\hline & 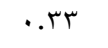 & r7o & 77.10 & داخل المجموعات & \\
\hline \multirow{2}{*}{ r.9r } & 1.19 & r & $r .70$ & بين المجموعات & \multirow{2}{*}{ المشاركة فى اتخاذ القرار البيئى } \\
\hline &. .4 & r7o & $\pi .94$ & داخل المجموعات & \\
\hline \multirow{2}{*}{ T.MT } & $0.7 \mathrm{~V}$ & r & 19.5 & بين المجموعات & \multirow[t]{2}{*}{ 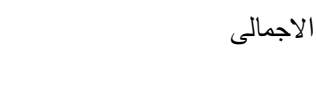 } \\
\hline & 1.51 & r7o & $190 . \leqslant r$ & داخل المجموعات & \\
\hline
\end{tabular}


(نظرية / عملية) وباستخدام اختبار (L.S.D) اتضح مصدر هذه الفروق الكليات النظرية، في حين بلفت قيمة ف

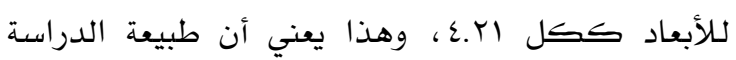

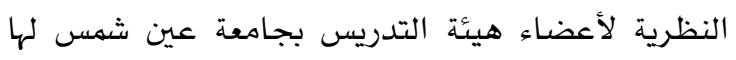

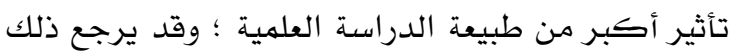

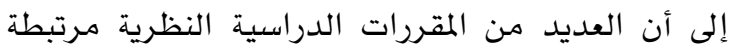

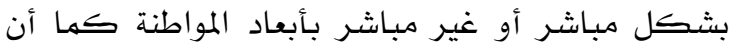
مجال البحث العلمى لأعضاء هيئة التدريس بجامعة عين لئن

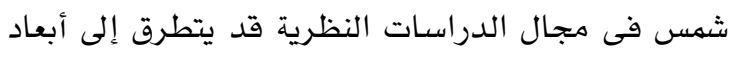
المواطنة البيئية. وقد اهتمت العديد من الدراسات بالكليات النظرية بتضمين أبعاد المواطنة فى المقررات

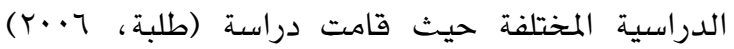
بوضع تصور مقترح لتفعيل دور التربية فى مجال حقوق

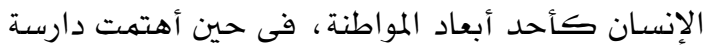
بتتمية المواطنة لمواجها التحديات (Stavenhagen, 2008)

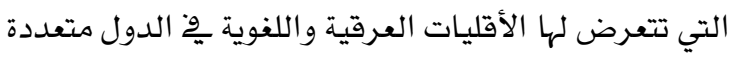

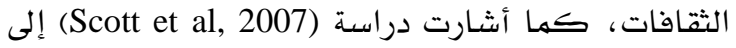
دور المناهج بِّ تتمية مفاهيم العدالة البيئية، فى حين أشارت دراسة (Sutton, 2009) إلى دور المناهج جِّْ تحقيق

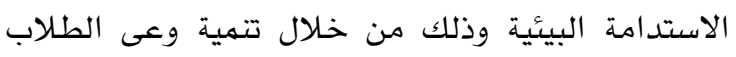

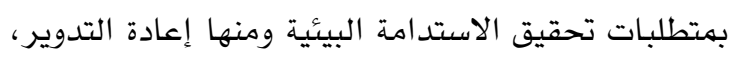
واستخدام كميات أقل من الماء الساخن، وتجنب منتجات السات المائه

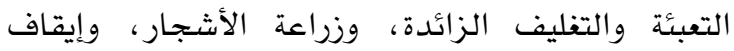
الأجهزة الإلكترونية عندما لا تكون قيد الاستخدام،

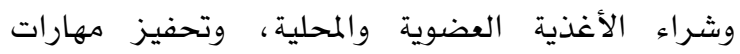

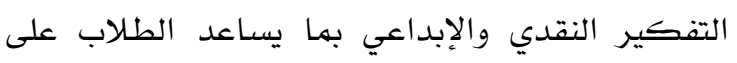
العيش ِّْ وئام مع البيئة، واحترام حق الإنسان والكائنات الحية ِِّْ الحياة، ودراسة(Berila, 2006) والتى أكدت على دور العدالة البيئية ِِّْ تدعيم مبدأ

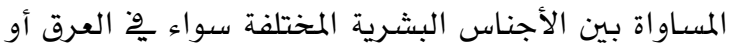

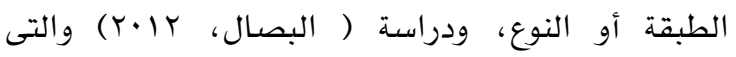

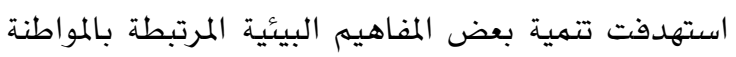

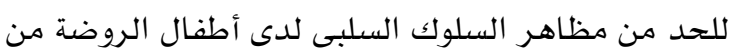
سن ع -7 سنوات من خلال برناهج إرشارى، وأخيرا دراسة (فراج، 10 أب) والتى استهدفت تقويم برنامج جلوب الدولى العلمى فى ضوء تحقيق الوعى البيئى لدى طلاب المرحلة الثانوية وأثره على المواطنة.
يتضح من جدول 0 وجود فروق ذات دلالة إحصائية عند مستوى دلالة 0. • بين متوسطات استجابات أفراد العينة نحو البعد الثالث، الخاص بالمشاركة في اتخاذ القرار

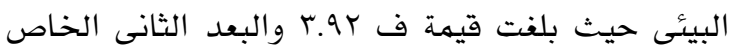
بالحقوق البيئية حيث بلفت قيمة ف Y.AV وذلك تبعا لمتفير الدرجة العلمية (مدرس/ أستاذ مساعد/ أستاذ). وباستخدام اختبار (L.S.D) اتضح مصدر هذه الفروق الفدرف وهو رتبة المدرس. فى حين بلغت قيمة ف للأبعاد ككل r.r. ويمكن تفسير هذه النتيجة على أساس اهتمام العديد من

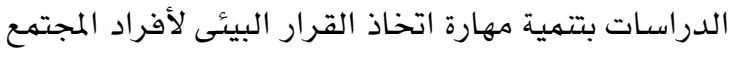

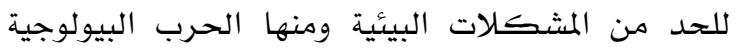

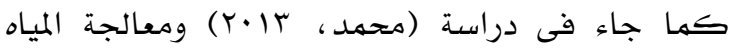

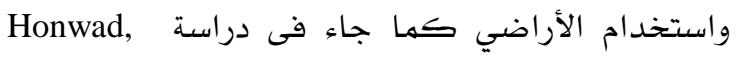
(2010) والمخلفات الالكترونية كما جاء فى دراسة الاراء

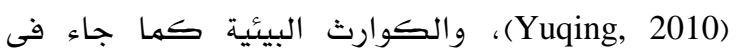

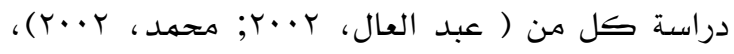
وتلوث البيئة المنزلية كما جاء فى دراسة (الحلبى،

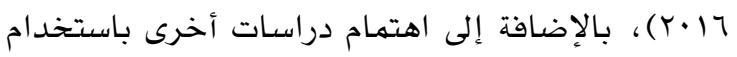

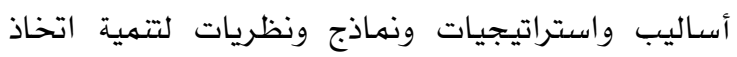

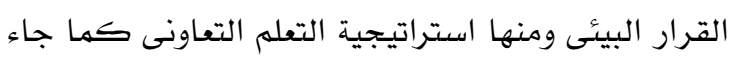

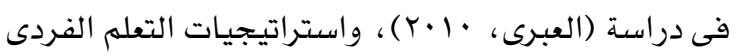

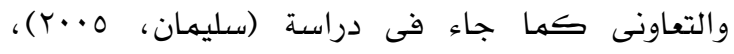
واستراتيجية التعلم المتمركز حول المشكلة كما جاء في دراسة (عبد العال، rا•Y) أو من خلال أساليب

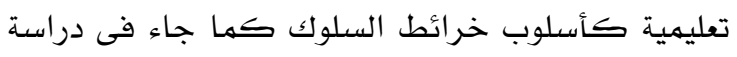
(نوير، 9. (Y)، أو من خلال استخدام نماذج تعليمية

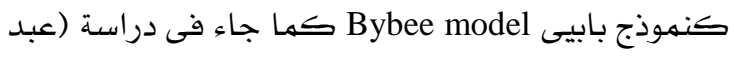
الرازق، (Y.1)، أو من خلال استخدام نظريات كالنظرية البنائية كما جاء فى دراسة (سلام، عالـب).

\section{درجة تصور أعضاء هيئة التدريس لأبعاد المواطنة البيئية} تبعا لمتفير الكلية ( نظرية / عملية)

يتضح من جدول 7 وجود فروق ذات دلالة إحصائية عند مستوى دلالة م.. بين متوسطات استجابات أفراد عينة البحث نحو البعد الثانى الخاص بالحقوق البيئية حيث بلغت قيمة ف با.بr وذلك تبعا لمتغير طبيعة الكلية 
جدول 1

تحليل التباين لاستجابات أعضاء هيئة التريس لأبعاد المواطنة البيئية تبعا لمتغير الكلية

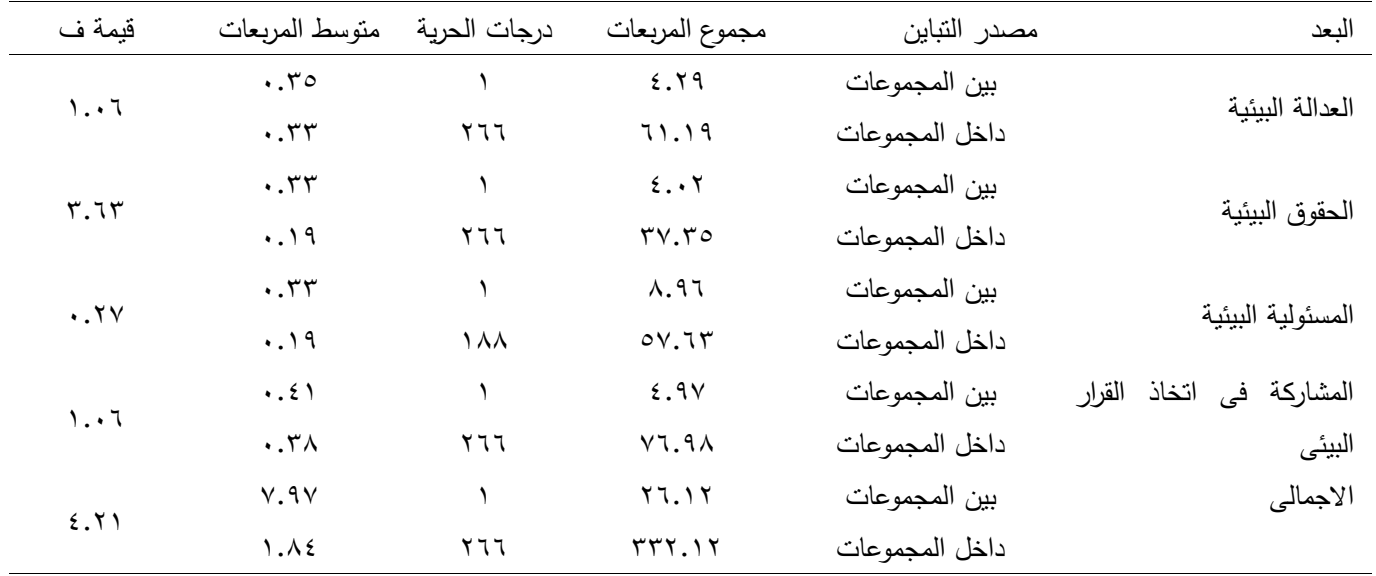

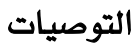

إبراهيم، مفيدة هلال (Y. (Y). تقويم المسئولية البيئية لدى تلاميذ المرحلة الاعدادية. رسالة ماجستير غير

منشورة، معهد الدراسات والبحوث البيئية، جامعة لهاهيد

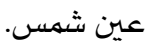

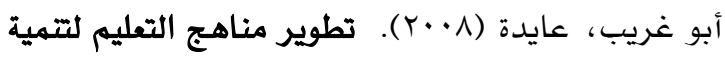
المواطنة فى الألفية الثالثة لدى الطلاب بالمرحلة الثانوية. المؤتمر العلمي الأول: تربية المواطنة ومناهج الدراسات الاجتماعية، الذي عقدته الدهائه

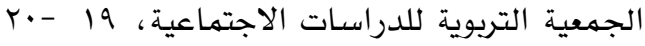
يونيو، دار الضيافة، جامعة عين شمس، (1)،

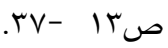

إسماعيل، ماهر وعبد الراضي، ناهد (.....) . فاعلية استخدام نهوذج التدريس الواقعى فى تتمية فهم القضايا الناتجة عن تفاعل العلم والتكنولوجيا

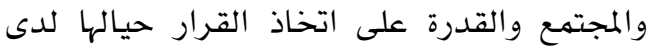
طالبات شعبة الفيزياء والكيمياء ذوات أساليب التفكير المختلفة بكلية التربية للبنات بالرستاق (سلطنة عمان)، مجلة التربية العلمية، الجمعية المصرية للتربية العلمية، ب(ع)، ديسمبر، .IVV- ص

أمين، هبة الله سامح كامل (Y Y T) . أثر التسعير على الحق الانسانى فى المياه. رسالة ماجستير غير منشورة، كلية الاقتصاد والعلوم السياسية،

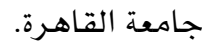

فى ضوء نتائج البحث توصى الباحثة بما يلى:

1. أهمية التعرف على تصورات أعضاء هيئة التدريس بالجامعات المصرية حول أبعاد المواطنة البيئية. - n r. تقويم أداء أعضاء هيئة التدريس بالجامعات المصرية فى ضوء قائمة أبعاد المواطنة البيئية. r. تفعيل دور الجامعات پِّ تتمية المواطنة البيئية لدى أعضاء هيئة التدريس من خلال تضمين الخطط الدراسية بهساقات تعزز أبعاد المواطنة

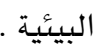
ع. تبني فلسفات الجامعات المصرية لقيم المواطنة البيئية وتفعيلها نظريا وتطبيقيا داخل كلياتها

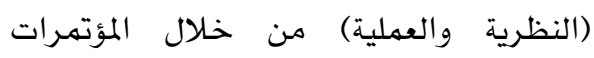
والندوات،والمقررات الدراسية.

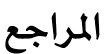

\section{References}

إبن منظور (Y.... (Y). لسان العرب. طا، دار صادر للطبع

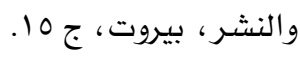

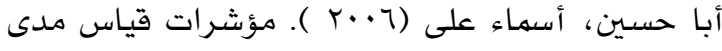
تحقيق المواطنة البيئية. مجلة العلوم الاجتماعية،

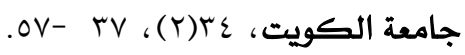


المنظور الحقوفي واشكاليات الواقع. عمان:

$$
\text { المركز الوطني لحقوق الانسان. }
$$

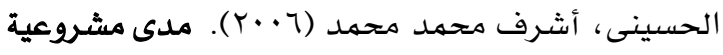

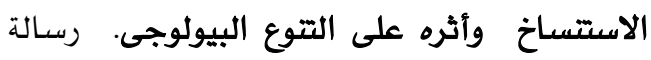

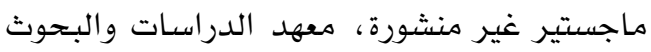

$$
\text { البيئية، جامعة عين شمس . }
$$

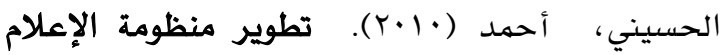

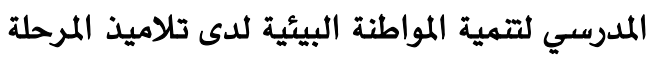
المتوسطة ِّْ دولة الكويت. رسالة دكتوراه غير

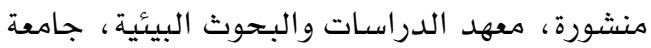
عين شهس.

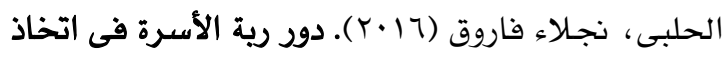
القرارات الخاصة بحماية البيئة المنزلية من التلوث. رسالة ماجستير غير منشورة، كلية الاقتصاد

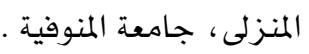

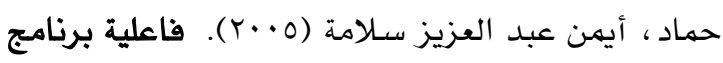
لتعديل السلوك وتتمية المسئولية الاجتماعية نحو البيئة لتلاميذ الحلقة الثانية من التعليم الأساسى. رسالة دكتوراه غير منشورة، معهد الدراسات العليا للطفولة، جامعة عين شمس.

حنفى، إيناس محمود (·(Y). ت تمية مهارات المواطنة

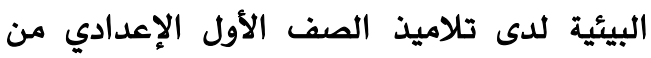

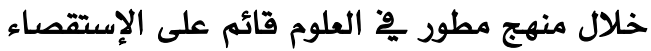
وحل المشكلات. رسالة دكتوراة غير منشورة، معهد الدراسات والبحوث البيئية، جامعة عين شهس.

حواس، مصباح عبد الله عبد القادر (11) (Y). أساس وطرق التعويض عن الأضرار البيئية ( دراسة

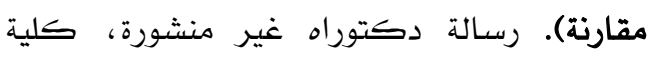

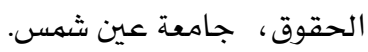

الخدرى، جميل حمود أحمد (11) (Y). فاعلية منهج مقترح فى التربية البيئية لطلاب كلية التربية بجامعة عمران باليمن لتتمية المسئولية البيئية. رسالة دكتوراه غير منشورة، معهد الدراسات

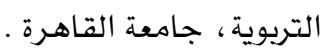

بدوي، احمد زكي (r/911) ـ معجم مصطلحات العلوم الاجتماعية. بيروت: مكتبة لبنان. البصال، إيناس السيد سادات (Y (Y). فعالية برنامج إرشارى فى تمية بعض المفاهيم البيئية المرتبطة بالمواطنة للحد من مظاهر السلوك السلبى لدى لئى أطفال الروضة من سن (ع -7سنوات ). رسالة ماجستير غير منشورة، كلية رياض الاطفال، جامعة بورسعيد. التركاوى، عمار خليل (Y.・). مسئولية الدولة عن أضرار التلوث البيئى (دراسة مقارنة). رسالة دكتوراه غير منشورة، كلية الحقوق، جامعة عين

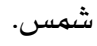

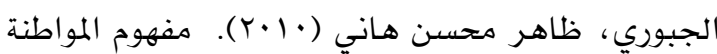
لدى طلبة الجامعة دراسة ميدانية لطلبة جامعة بابل. مجلة جامعة بابل،العلوم الإنسانية، \(1)، (1)،

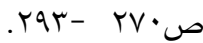
الجرهومى، محمد على حسين (Y (Y). التعويض عن الأضرار البيئية فى نطاق القانون الدولى. رسالة

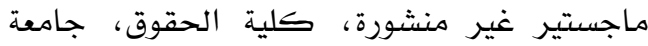
أسيوط. - أن

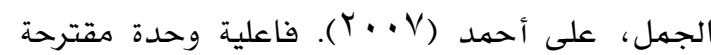
بمنهج التاريخ الإسلامى بالمرحلة الإعدادية قائمة على قيم المواطنة ِِّْ تتمية الوعى بالمسئولية

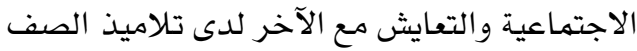
الثانى الإعدادي. مجلة الجمعية التربوية للدراسات

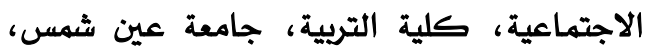

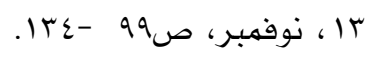
حسانين، أبو بكر حمدى محمد محمد (Y (Y). تطوير

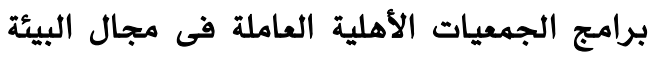

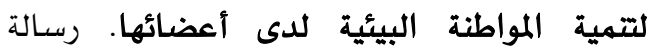
دكتوراة غير منشورة، معهد الدراسات والبحوث البيئية ، جامعة عين شمس. الحسبان، عيد (11 (Y). المقاريات القانونية لمبدأ المواطنة هِخ المنظومة التشريعية الأردنية ودلالات الممارسات السياسية، وقائع الندوة الفكرية المواطنة بين 
شعبان، أيهن عفيفى شعبان (ب0.0). التعويض عن أضرار البيئة فى محيط الجوار. رسـالة ماجستير غير منشورة ، كلية الحقوق، جامعة عين شمس . طلبه، جابر محمود (Y7) (†). التربية على حقوق الإنسان فى النظام التعليمى فى مصر (مدخل لفهم حقوق الطفل). ورقة عمل مقدمة إلى المؤتهر العلهى الثالث لمركز رعاية وتتهية الطفولة التربية وحقوق الطفل فى الوطن العربى بين التشريع والتطبيق، مارس، جامعة المنصورة. طلعت، حمدي (1) (Y). فاعلية برنامج مقترح قائم على إستراتيجية التعلم التعاوني لتتمية المواطنة البيئية لدى تلاميذ المرحلة الإعدادية. رسالة ماجستير غير منشورة، معهد الدراسـات والبحوث البيئية، جامعة لمايدة عين شهس. عبد الرازق، السعيد محمد محمود (·+ (ب). فاعلية نموذج بابيى Bybee model فى تحصيل الأحياء

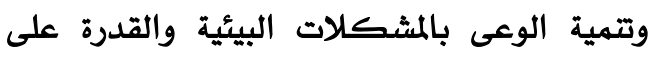
إتخاذ القرار تجاهها لدى طلاب المرحلة الثانوية. رسالة ماجستير غير منشورة، كلية التربية، جامعة

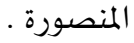

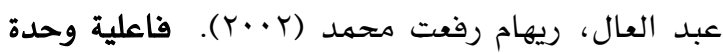
مطورة فى الكوارث الطبيعية لتحقيق بعض أبعاد التربية الوقائية فى الجفرافيا لدى تلاميذ الصف الأول الاعدادى. رسالة ماجستير غير منشورة، كلية البنات للآداب والعلوم والتربية، جامعة عين شهس.

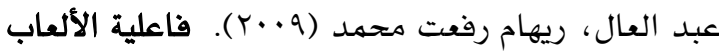
التعليمية فى تتمية الوعي بالحقوق البيئية للطفل ومهارة اتخاذ القرار لدى تلميذات الحلقة الأولى من التعليم الأساسى. المؤتهر الدولي الخامس للبحوث

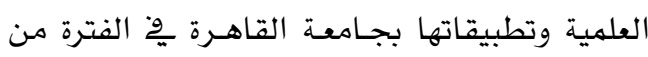

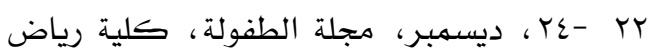

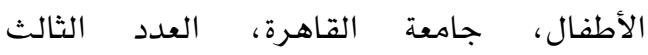

$$
\text { الاستثائي، صلV. }
$$

الدجاني، احمد صدقي (1999). مسلمون ومسيحيون مو الحضارة العريية الإسلامية. القاهرة. مركز يافا للدراسـات والأبحاث.

الرافعي، محب محمود كامل (^^ ㄷ). المواطنة البيئية، ورقة عمل مقدمة ِِّ المؤتمر القومي للتوعية والإرشاد من مخاطر التلوث البيئي، مشروع المواطنة البيئية. المركز الثقايِ، وزارة الدولة لشئون البيئة ، با نوفمبر. المبهر. السـاعدى، عائثة محمد اوحيدة (ع| •Y). برنامج مقترح للعلوم البيئية لتتمية أبعاد المواطنة البيئية للطلاب المعلمين بكلية التربية بليبيا. رسـالة ماجستير غير

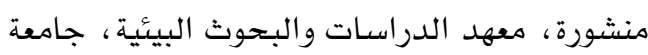
عين شهس. سـلام، باسهم صبرى محمد (عا +ץ). فاعلية برنامج فى الدراسات الاجتماعية قائم على النظرية البنائية لتتمية بعض المفاهيم والوعى الأمانى ومهارات اتخاذ القرار لدى تلاميذ المرحلة الإعدادية. رسالة دكتوراه غير منشورة، كلية التربية، جامعة

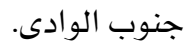

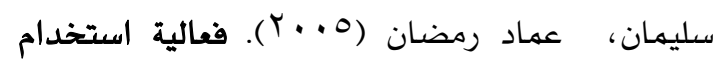
استراتيجيات متعددة من خلال منهج التاريخ على تتمية القيم البيئية ومهارات اتخاذ القرار لدى طلاب المرحلة الثانوية. رسالة دكتوراة غير منشورة، معهد الدراسات والبحوث البيئية ، جامعة البـات عين شمس. شحادة، موسى مصطفى (YV). (Y). الحق فى الحصول على المعلومات فى مجال البيئة حق من الحقوق الاسـاسية للإنسان، مجلة الشريعة والقانون، كلية القانون، جامعة الإمارات العريية المتحدة،

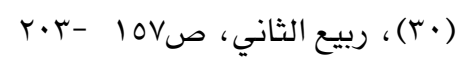

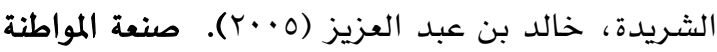
مِ عالم متغير. دراسـة مقدمة للقاء السنوي الثالث عشر لقادة العمل التربوي، الباحة، المملكة العربية

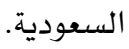




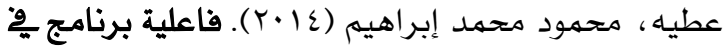
أنشطة بيئية مصاحبة لمنهج الدراسات الإجتماعية لتمية بعض أبعاد المواطنة البيئية لدى تلاميذ الصف الأول الإعدادي. رسالة ماجستير غير

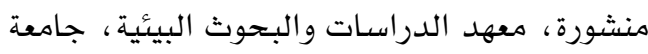
عين شمس.

عفيفى، أمال حمد شعبان (Y/.r). دور المراكز الاستكشافية العلمية فى تمية المسئولية الاجتماعية نحو البيئة. رسالة ماجستير غير منشورة، معهد الدراسـات والبحوث البيئية، جامعة البهائ عين شمس. على، شيخة ريحان وأبا حسين، أسماء على والعجب، العجب محمد وعبده، أنور شيخ الدين (10) إب). تصسيم وحدة تعليمية الكترونية إثرائية عن المواطنة البيئية ومواضيع الوهـابك وقياس أثره على المخرجات التعليمية لدى طلبه المرحلة الإبتدائية فى دولة الكويت. مجلة التعاون، الأمانة العامة لمجلس

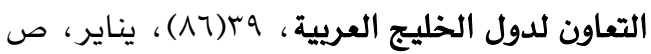
$.7 \cdot-19$ على، إنجي صلاح الدين إبراهيم (11 (ب). وحدة مقترحة قائمة على المواطنة البيئية ِِخ تدريس الدراسات الإجتماعية لتتمية القيم البيئية لدى طلاب المرحلة الإعدادية. رسالة ماجستير غير منشورة، كلية التربية ، جامعة عين شمس الهس

غندور، مالك (0 ㄱ). المواطنة البيئية (قيم - مفاهيم - حقوق - واجبات). ورقة عمل مقدمة إلى المؤتهر

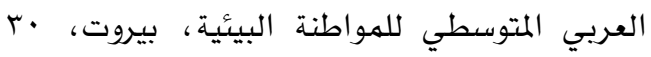
مارس. فراج، مروة عبد الله مصطفى (10 • ( ). تقويم برنامج جلوب الدولى العلمى فى ضوء تحقيق الوعى البيئى لدى طلاب المرحلة الثانوية وأثره على المواطنة. رسالة ماجستير غير منشورة، كلية التربية جامعة عين شهس. كاظم، ثائر رحيم (9.9) . . العولمة والمواطنة والهوية (بحث فى تأثير العولمة على الإنتهاء الوطنى والمحلى
عبد العال، ريهام رفعت محمد (Y| •Y) . تصور مقترح لتضهـين بعض مبادئ العدالة البيئية ِِّ مناهـج الدراسـات الاجتماعية بهرحلة التعليم الأساسي بجمهورية مصر العربية. مجلة العلوم التربوية

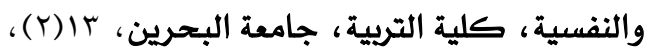

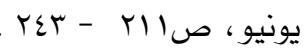

عبد العال، ريهام رفعت محمد (Y| • (Y) . فاعلية استخدام استراتيجية التعلم المتمركز حول المشكلة فى تدريس وحدة "الإإنسان والبيئة فى بلدى" بهنهج الدراسات الاجتماعية فى تتمية مهارات التقكير العلمى وإتخاذ القرارات البيئية لدى تلميذات الصف الرابع الابتدائى. مجلة كلية التربية، جامعة

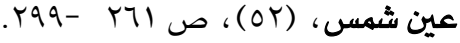
عبد العزيز ، رشا أحمد على (10 • (Y). فاعلية برنامج قائم على التعلم الذاتى فى تتمية الوعى بالتشريعات البيئية لدى طلاب الجامعات. رسـالة ماجستير غير منشورة، معهد الدراسات والبحوث البيئية، جامعة عين شهس. عبده، وائل محمد رضا (11) الاجتماعية للشباب فى العمل البيئى ( دراسة مقارنة لعينة من الذكور والأناث فى بعض منظمات المجتمع المدنى). رسالة ماجستير غير

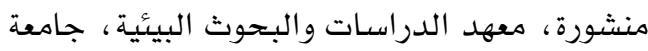
عين شمس.

العبرى، ناصر بن عبد الله بن حمدان (• (ب). فاعلية وحدة مقترحة فى التربية البيئية قائمة على التعلم التعاونى فى تتمية الاتجاهات البيئية ومهارات

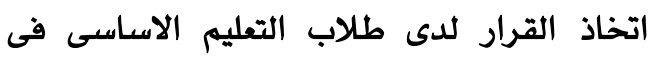
سلطنة عمان (الحلقة الثانية). رسالة ماجستير غير منشورة، معهد الدراسـات والبحوث البيئية، جامعة عين شمس.

عزوز، بدر عبد المحسن (11 (Y). حق الانسان فى بيئة نظيفة. رسالة دكتوراه غير منشورة، كلية الحقوق، جامعة عين شمس. 
للمرأة والرجيم الغذائى. مجلة أسيوط للدراسات

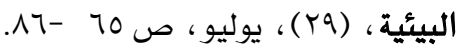

Barry, J. (2006). Resistance is fertile: From environmental to sustainability citizenship. In, Andrew Dobson and Derek Bell (eds.), Environmental Citizenship ( $p p$ 21-48). Cambridge, MA: The MIT Press..

Basile, Carole; White, Cameron(2000) Literacy As a Stepping Stone to Environmental Citizenship. Clearing, 107, p 9-13 Fall

Berila, B.(2006). The Links between Environmental Justice and Feminist Pedagogy: An Introduction, Feminist Teacher , A Journal of the Practices. Theories, and Scholarship of Feminist Teaching, (16)2, 93-97

Bowers, C. ( 2002) . Toward an Eco-justice Pedagogy. Environmental Education Research, (8)1, p 21-34

Chung, R. (2005). "Women, Human Rights, and Counseling: Crossing International Boundaries", Journal of Counseling \& Development, Sum (83)3, 262-268

De Silva, R. (2008). "Disability Rights, Gender, and Development: A Resource Tool for Action". Full Report, Wellesley Centers for Women

Dean, H. (2001). Green citizenship. Social Policy and Administration 35(5), 490-505.

Derek, B. (2005). Liberal Environmental Citizenship " Environmental Politics, University of Newcastle, Newcastle upon Tyne, UK, April (14)2, 179 - 194. Retrived From: www.environinfo.org/what is environmental citizenship.html

Dimick, A. (2015). Supporting Youth to Develop Environmental Citizenship Within/Against a Neoliberal Context. Environmental Education Research, 21(3), 390402

Dobson, A. \& Derek, B. ( 2005). Environmental Citizenship the Good enough primer, London.

Dobson, A. \& Derek B (2006). Introduction In Environmental Citizenship. Cambridge, MA: The MIT Press, 1-17

Dobson, A. (2003). Citizenship and the Environment. Oxford: Oxford, University Press.

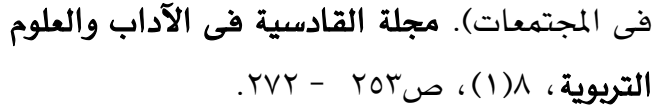


Dobson. A. \& Bell, D. (2005). Environmental Citizenship the Good enough primer, London

Erbas, A. et al (2012). An evaluation of environmental responsibility and Its associated factors: reflections from PISA 2006. Eurasian Journal of Educational Research, (46), p 41-62

Florida State Dept. of Environmental Protection, Tallahassee (2000) Environmental Citizenship in Florida's Middle Schools Washingto. Distributed by ERIC Clearinghouse

Foo, S. \& Starlin, C. (2006). Building A Culture Of Peace For A Civil Society, World Council for Curriculum and Instruction, Papers presented at the 12th World Conference on Education of the World Council for Curriculum \& Instruction (Manila, Philippines, Aug 6-12

Gebbels, S.; Evans, S. M.; Delany, J. E. (2011). Promoting Environmental Citizenship and Corporate Social Responsibility through a School/Industry/University Partnership. Journal of Biological Education, 45(1), 13-19

Green, C.; Medina, J., William; B. C. (2016) Cultivating Environmental Citizenship in Teacher Education. Teaching Education, 27(2), 117-135

Hailwood, S. Environmental Politics, 14(2), 195210.

Holmes, C. (1980). Social Knowledge and Citizenship Education : Two views Of Truth and Criticism. Curriculum in Quity, 10(2), 110-115.

Honwad, S. (2010). Use of Indigenous Knowledge in Environmental Decision-Making by Communities in the Kumaon Himalayas (ED521265), ProQuest LLC, Ph.D. Dissertation, The Pennsylvania State University

Hung, R. (2007). Is Ecological Sustainability Consonant or Dissonant with Human Rights? Identifying Theoretical Issues in Peace Education. Journal of Peace Education Mar. (4)1, 39-55

Hungerford, H. (1996). The Development of Responsible Environmental Citizenship: A Critical Challenge. Journal of Interpretation Research, 1(1), 25-37
Hungerford, H. R., \& Volk, T. L., (1990). Changing learner behavior through environmental education. Journal of Environmental Education, 21(3), 8-21.

John, J. et al (2000). Citizenship for the 21st Century: An International Perspective on Education. Psychology Press, p 3-5.

Juilie, B. et al (2005). Environmental Citizenship: Literature Review, Environment Agency. Rio house, Aztec west Almondsbury, Bristol, U.K, May.

Julie, S. (2006). Pollution, and Environmental Justice. Feminist Teacher: A Journal of the Practices, Theories, and Scholarship of Feminist Teaching, 16(2), 124-132

Killeen, S. (2006). Using science to create a better place Environmental Citizenship Literature Review, Environment Agency, Rio House, Waterside Drive, Aztec West, Almondsbury, Bristol

King, T. (2004). Development of environmental citizenship in students in Hong Kong (China). PhD, NO: AAI0806921

Kushmerick, A. et al (2007). Environmental Justice Content in Mainstream US, 6-12 Environmental Education Guides. Environmental Education Research, 13(3), 385408

Lewis, J. (1998). I Can Be an Environmental Citizen: An Environmental Citizenship Handbook for Young People. Washington, Distributed by ERIC Clearinghouse.

Luque, E. (2005). Researching environmental citizenship and its publics.Environmental Politics, 14(2), 212-225

Lysack, M. (2009). The Teach-in on Global Warming Solutions and Vygotsky: Fostering Ecological Action and Environmental Citizenship, McGill Journal of Education, 44(1) ,p119-134

MacGregor, S. (2006) . Beyond Mothering Earth: Ecological Citizenship and the Politics of Care. Vancouver: UBC Press.

MacPherson, S. (2005). Ducating Ecological Citizens of "The Blue Planet". Canadian Journal of Environmental Education, 10(1), 141-156

North American Association of Environmental Education (NAEEE). (2006). Excellence in 


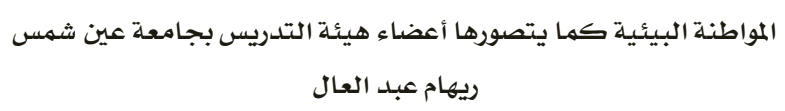

education guidelines. Guidelines for 12th grade.From:

http:/ / naaee.org/npeee/learnerguidelines /12th.pdf

Nowak, Amy L. Versnik; Hale, Heidi; Lindholm, Jessica; Strausser, Elizabeth (2009). he Story of Stuff: Increasing Environmental Citizenship. American Journal of Health Education, 40(6), 346-354 Nov-Dec

Robinson, Zoe P. (2015). Are Geography Students Good "Environmental Citizens?" A Comparison between Year of Study and over Time. Journal of Geography in Higher Education, 39(2), 245-259

Ruth, F. (2008). OSCE Human Dimension Implementation Meeting, Session 8 on Education and Awareness Raising in the Promotion of Human Rights. October 3rd From:

http:/ / www.ceji.org/press/OOSCE\%20M eeting $\% 20 I I \% 202008$.pdf

Scott, W. etal (2007). Engaging Children, Research Issues around Participation and Environmental. Education Research, Sep 13(4), 529-544

Selby, D. (2000). Weaving connections: Educating for peace, social and environmental justice books. Collected Works - General

Seyfang, G. (2006). Ecological citizenship and sustainable consumption: examining local organic food Networks. Journal of Rural Studies, 22(4), 383-395

Skye, L. (2004). A description of adult environmental education programs in residential environmental education centers: Their use of experiential learning theory and environmental citizenship concepts. PhD. University-of-Idaho, USA

Smith, G. (2005). Green citizenship and the social economy. Environmental Politics 14(2), 273-289

Smith, M. (1998). Ecologism: Towards ecological citizenship. Milton Keynes: Open University Press.

Stavenhagen, R. (2008). building intercultural citizenship through education: a human rights approach. European Journal of Education, 43(2), 161-179
Sutton, A. (2009). Educating for Ecological sustainability: Montessori education leads the way, Montessori Life: A Publication of the American Montessori Society, 21(4), 18-25

Syed, K. (2008). Misconceptions about human rights and women's rights in Islam. Interchange: A Quarterly Review of Education, 39(2), 245-257

Tarrant, Michael; Lyons, Kevin (2012). The Effect of Short-Term Educational Travel Programs on Environmental Citizenship. Environmental Education Research, 18(3), 403416

United Nations Environment Programme (UNEP). (2004). Environmental Citizenship: An Introductory Guidebook on Building Partnerships between Citizens and Local Governments for Environmental Sustainability. Integrative Management Series

Weilbacher, M.(2009). He Window into Green. Educational Leadership, 66(8), 38-44

Yuqing, Y. (2010). Adults' Decision-Making about the Electronic Waste Issue: The Role of the Nature of Science. Conceptualizations and Moral Concerns in Socio-Scientific DecisionMaking (ED514172), ProQuest LLC, Ph.D. Dissertation, Columbia University.

Zand, R. (2008). Frequency and Correlates of Spouse Abuse by Type: Physical, Sexual and Psychological Battering among a Sample of Iranian Women, International Journal of Mental Health and Addiction, Jul (6)3, p 432-441. 